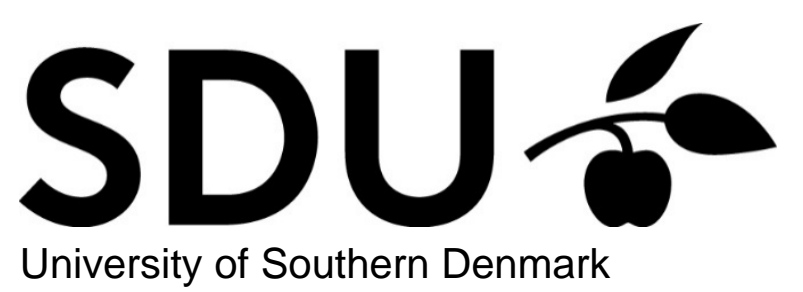

\title{
Adherence to treatment in allergic rhinitis using mobile technology. the mask study
}

Menditto, E; Costa, E; Midão, L; Bosnic-Anticevich, S; Novellino, E; Bialek, S; Briedis, V; Mair, A; Rajabian-Soderlund, R; Arnavielhe, S; Bedbrook, A; Czarlewski, W; Annesi-Maesano, I; Anto, J M; Devillier, P; De Vries, G; Keil, T; Sheikh, A; Orlando, V; Larenas-Linnemann, D; Cecchi, L; De Feo, G; Illario, M; Stellato, C; Fonseca, J; Malva, J; Morais-Almeida, M; Pereira, A M; Todo-Bom, A; Kvedariene, V; Valiulis, A; Bergmann, K C; Klimek, L; Mösges, R; Pfaar, O; Zuberbier, T; Cardona, V; Mullol, J; Papadopoulos, N G; Prokopakis, E P; Bewick, M;

Ryan, D; Roller-Wirnsberger, R E; Tomazic, P V; Cruz, A A; Kuna, P; Samolinski, B; Fokkens, W J; Bindslev-Jensen, C; Eller, E; MASK group

Published in:

Clinical and Experimental Allergy

DOI:

10.1111/cea.13333

Publication date:

2019

Document version

Accepted manuscript

Citation for pulished version (APA):

Menditto, E., Costa, E., Midão, L., Bosnic-Anticevich, S., Novellino, E., Bialek, S., Briedis, V., Mair, A., RajabianSoderlund, R., Arnavielhe, S., Bedbrook, A., Czarlewski, W., Annesi-Maesano, I., Anto, J. M., Devillier, P., De Vries, G., Keil, T., Sheikh, A., Orlando, V., ... MASK group (2019). Adherence to treatment in allergic rhinitis using mobile technology. the mask study. Clinical and Experimental Allergy, 49(4), 442-460.

https://doi.org/10.1111/cea.13333

\section{Terms of use}

This work is brought to you by the University of Southern Denmark through the SDU Research Portal.

Unless otherwise specified it has been shared according to the terms for self-archiving.

If no other license is stated, these terms apply:

- You may download this work for personal use only.

- You may not further distribute the material or use it for any profit-making activity or commercial gain

- You may freely distribute the URL identifying this open access version 


\section{ARTICLE TYPE: ORIGINAL ARTICLE-ASTHMA AND RHINITIS}

\section{ADHERENCE TO TREATMENT IN ALLERGIC RHINITIS USING MOBILE TECHNOLOGY. THE MASK STUDY}

\section{SHORT TITLE: ADHERENCE TO TREATMENT IN THE MASK STUDY}

E Menditto (1), E Costa (2), L Midão (2), S Bosnic-Anticevich (3), E Novellino (4), S Bialek (5), V Briedis (6), A Mair (7), R Rajabian-Soderlund (8), S Arnavielhe (9), A Bedbrook (10), W Czarlewski (11), I AnnesiMaesano (12), JM Anto (13-16), P Devillier (17), G De Vries (18), T Keil (19), A Sheikh (20), V Orlando (1), D Larenas-Linnemann (21), L Cecchi (22), G De Feo (23), M Illario (24), C Stellato (23), J Fonseca (25), J Malva (26), M Morais-Almeida (27) , AM Pereira (28), A Todo-Bom (29), V Kvedariene (30), A Valiulis (31), KC Bergmann (32), L Klimek (33), R Mösges (34), O Pfaar (33,35), T Zuberbier (32), V Cardona (36), J Mullol (37) , NG Papadopoulos (38), EP Prokopakis (39), M Bewick (40), D Ryan (41), RE RollerWirnsberger (61), PV Tomazic (42), AA Cruz (43), P Kuna (44), B Samolinski (45), WJ Fokkens (46), S Reitsma (46), I Bosse (47), JF Fontaine (48), D Laune (9), T Haahtela (49), S Toppila-Salmi (49), C Bachert (50), PW Hellings (51), E Melén (52), M Wickman (53), C Bindslev-Jensen (54), E Eller (54), RE O’Hehir (55), C Cingi (56), B Gemicioğlu (57), O Kalayci (58), JC Ivancevich (59), J Bousquet $(10,60)$ and the MASK group

1. CIRFF, Center of Pharmacoeconomics, University of Naples Federico II, Naples, Italy.

2. UCIBIO, REQUIMTE, Faculty of Pharmacy, and Competence Center on Active and Healthy Ageing of University of Porto (Porto4Ageing), University of Porto, Portugal.

3. Woolcock Institute of Medical Research, University of Sydney Woolcock Emphysema Centre and Sydney Local Health District, Glebe, NSW, Australia.

4. Director of Department of Pharmacy of University of Naples Federico II, Naples, Italy.

5. Department of Biochemistry and Clinical Chemistry, Faculty of Pharmacy with the Division of Laboratory Medicine, Warsaw Medical University, Warsaw, Poland.

6. Head of Department of Clinical Pharmacy of Lithuanian University of Health Sciences, Kaunas, Lithuania.

7. DG for Health and Social Care, Scottish Government, Edinburgh, UK.

8. Department of Nephrology and Endocrinology, Karolinska University Hospital, Stockholm, Sweden.

9. KYomed INNOV, Montpellier, France.

10. MACVIA-France, Fondation partenariale FMC VIA-LR, Montpellier, France.

11. Medical Consulting Czarlewski, Levallois, France.

12. Epidemiology of Allergic and Respiratory Diseases, Department Institute Pierre Louis of Epidemiology and Public Health, INSERM and Sorbonne Université, Medical School Saint Antoine, Paris, France.

13. ISGlobAL, Centre for Research in Environmental Epidemiology (CREAL), Barcelona, Spain.

14. IMIM (Hospital del Mar Research Institute), Barcelona, Spain.

15. CIBER Epidemiología y Salud Pública (CIBERESP), Barcelona, Spain.

16. Universitat Pompeu Fabra (UPF), Barcelona, Spain.

This article has been accepted for publication and undergone full peer review but has not been through the copyediting, typesetting, pagination and proofreading process, which may lead to differences between this version and the Version of Record. Please cite this article as doi: $10.1111 /$ cea.13333

This article is protected by copyright. All rights reserved. 
17. Laboratoire de Pharmacologie Respiratoire UPRES EA220, Hôpital Foch, Suresnes, Université Versailles Saint-Quentin, Université Paris Saclay, France.

18. Peercode BV, Geldermalsen, The Netherlands.

19. Institute of Social Medicine, Epidemiology and Health Economics, Charité - Universitätsmedizin Berlin, Berlin, and Institute for Clinical Epidemiology and Biometry, University of Wuerzburg, Germany.

20. The Usher Institute of Population Health Sciences and Informatics, The University of Edinburgh, Edinburgh, UK.

21. Center of Excellence in Asthma and Allergy, Médica Sur Clinical Foundation and Hospital, México City, Mexico.

22. SOS Allergology and Clinical Immunology, USL Toscana Centro, Prato, Italy.

23. Department of Medicine, Surgery and Dentistry "Scuola Medica Salernitana", University of Salerno, Salerno, Italy.

24. Division for Health Innovation, Campania Region and Federico II University Hospital Naples (R\&D and DISMET) Naples, Italy.

25. CINTESIS, Center for Research in Health Technologies and Information Systems, Faculdade de Medicina da Universidade do Porto, Porto, Portugal and MEDIDA, Lda, Porto, Portugal.

26. Coimbra Institute for Clinical and Biomedical Research (iCBR), Faculty of Medicine, University of Coimbra, Portugal; Ageing@Coimbra EIP-AHA Reference Site, Coimbra, Portugal.

27. Allergy Center, CUF Descobertas Hospital, Lisbon, Portugal.

28. Allergy Unit, CUF-Porto Hospital and Institute; Center for Research in Health Technologies and information systems CINTESIS, Universidade do Porto, Portugal.

29. Imunoalergologia, Centro Hospitalar Universitário de Coimbra and Faculty of Medicine, University of Coimbra, Portugal.

30. Faculty of Medicine, Vilnius University, Vilnius, Lithuania.

31. Vilnius University Institute of Clinical Medicine, Clinic of Children's Diseases, and Institute of Health Sciences, Department of Public Health, Vilnius, Lithuania; European Academy of Paediatrics (EAP/UEMS$\mathrm{SP})$, Brussels, Belgium.

32. Charité - Universitätsmedizin Berlin, corporate member of Freie Universität Berlin, Humboldt-Universität zu Berlin, and Berlin Institute of Health, Comprehensive Allergy Center, Department of Dermatology and Allergy, a member of $\mathrm{GA}^{2} \mathrm{LEN}$, Berlin, Germany.

33. Center for Rhinology and Allergology, Wiesbaden, Germany.

34. Institute of Medical Statistics, and Computational Biology, Medical Faculty, University of Cologne, Germany and CRI-Clinical Research International-Ltd, Hamburg, Germany.

35. Department of Otorhinolaryngology, Head and Neck Surgery, Universitätsmedizin Mannheim, Medical Faculty Mannheim, Heidelberg University, Mannheim, Germany.

36. Allergy Section, Department of Internal Medicine, Hospital Vall d'Hebron, \& ARADyAL Spanish Research Network, Barcelona, Spain.

37. Rhinology Unit \& Smell Clinic, ENT Department, Hospital Clínic; Clinical \& Experimental Respiratory Immunoallergy, IDIBAPS, CIBERES, University of Barcelona, Spain.

38. Division of Infection, Immunity \& Respiratory Medicine, Royal Manchester Children's Hospital, University of Manchester, Manchester, UK, and Allergy Department, 2nd Pediatric Clinic, Athens General Children's Hospital "P\&A Kyriakou," University of Athens, Athens, Greece.

39. Department of Otorhinolaryngology University of Crete School of Medicine, Heraklion, Greece.

40. iQ4U Consultants Ltd, London, UK.

41. Honorary Clinical Research Fellow, Allergy and Respiratory Research Group, The University of Edinburgh, Edinburgh, Past President SLAAI, FACAAI, UK

42. Department of ENT, Medical University of Graz, Austria

43. ProAR - Nucleo de Excelencia em Asma, Federal University of Bahia, Brasil and WHO GARD Planning Group, Brazil.

44. Division of Internal Medicine, Asthma and Allergy, Barlicki University Hospital, Medical University of Lodz, Poland.

45. Department of Prevention of Envinronmental Hazards and Allergology, Medical University of Warsaw, Poland.

46. Department of Otorhinolaryngology, Academic Medical Centre, Amsterdam, the Netherlands.

47. Allergist, La Rochelle, France.

48. Allergist, Reims, France.

49. Skin and Allergy Hospital, Helsinki University Hospital and University of Helsinki, Helsinki, Finland.

This article is protected by copyright. All rights reserved. 
50. Upper Airways Research Laboratory, ENT Dept, Ghent University Hospital, Ghent, Belgium.

51. Dept of Otorhinolaryngology, Univ Hospitals Leuven, Belgium, and Academic Medical Center, Univ of Amsterdam, The Netherlands and Euforea, Brussels, Belgium.

52. Sachs' Children and Youth Hospital, Södersjukhuset, Stockholm and Institute of Environmental Medicine, Karolinska Institutet, Stockholm, Sweden.

53. Centre for Clinical Research Sörmland, Uppsala University, Eskilstuna, Sweden.

54. Department of Dermatology and Allergy Centre, Odense University Hospital, Odense Research Center for Anaphylaxis (ORCA), Odense, Denmark.

55. Department of Allergy, Immunology and Respiratory Medicine, Alfred Hospital and Central Clinical School, Monash University, Melbourne, Victoria, Australia; Department of Immunology, Monash University, Melbourne, Victoria, Australia.

56. Eskisehir Osmangazi University, Medical Faculty, ENT Department, Eskisehir,Turkey.

57. Department of Pulmonary Diseases, Istanbul University, Cerrahpasa Faculty of Medicine, Turkey.

58. Pediatric Allergy and Asthma Unit, Hacettepe University School of Medicine, Ankara, Turkey.

59. Servicio de Alergia e Immunologia, Clinica Santa Isabel, Buenos Aires, Argentina.

60. INSERM U 1168, VIMA : Ageing and chronic diseases Epidemiological and public health approaches, Villejuif, Université Versailles St-Quentin-en-Yvelines, UMR-S 1168, Montigny le Bretonneux, France and Euforea, Brussels, Belgium.

61. Department of Internal Medicine, Medical University of Graz, Austria

\section{Corresponding author}

Professor Jean Bousquet

CHU Montpellier, 371 Avenue du Doyen Gaston Giraud, 34295 Montpellier Cedex 5, France

Tel+33611428847 jean.bousquet@orange.fr

\section{Abstract}

Background: Mobile technology may help to better understand the adherence to treatment MASKrhinitis (Mobile Airways Sentinel Network for allergic rhinitis) is a patient-centered ICT system. A mobile phone app (the Allergy Diary) central to MASK is available in 22 countries.

Objectives: To assess the adherence to treatment in allergic rhinitis patients using the Allergy Diary App.

Methods: An observational cross-sectional study was carried out on all users who filled in the Allergy Diary from January 1, 2016 to August 1, 2017. Secondary adherence was assessed by using the modified Medication Possession Ratio (MPR) and the Proportion of days covered (PDC) approach.

This article is protected by copyright. All rights reserved. 
Results: 12,143 users were registered. 6,949 users reported at least one VAS data recording. Among them, 1,887 users reported $\geq 7$ VAS data. 1,195 subjects were included in the analysis of adherence. $136(11.28 \%)$ users were adherent (MPR $\geq 70 \%$ and PDC $\leq 1.25), 51$ (4.23\%) were partly adherent (MPR $\geq 70 \%$ and PDC $=1.50)$ and $176(14.60 \%)$ were switchers. On the other hand, 832 (69.05\%) users were non-adherent to medications (MPR<70\%). Of those, the largest group was non-adherent to medications and the time interval was increased in 442 (36.68\%) users.

Conclusion and clinical relevance: Adherence to treatment is low. The relative efficacy of continuous versus on-demand treatment for AR symptoms is still a matter of debate.This study shows an approach for measuring retrospective adherence based on a mobile app. This represent a novel approach also for analyzing medication taking behavior in a real-world setting.

Key words: mHealth, mobile technology, adherence, rhinitis, treatment, observational study

\section{Abbreviations}

AR: Allergic rhinitis

ARIA: Allergic Rhinitis and Its Impact on Asthma

MASK: Mobile ARIA Sentinel network

mHealth: mobile health

MPR: Medication Possession Ratio

OTC: Over the counter

PDC: Proportion of Days Covered

QOL: Quality of life

VAS: Visual analogue scale

\section{Introduction}

Globally, non-adherence to medications is a major obstacle to the effective delivery of health care. Medication adherence and medication persistence are two different constructs. Medication adherence is defined as an active, cooperative and voluntary participation of the patient on following recommendations from a healthcare provider. This is a multifactorial behaviour that involves three critical steps, including initiation, implementation and discontinuation (1). Medication

This article is protected by copyright. All rights reserved. 
persistence refers to the act of continuing the treatment for the prescribed duration (2). In research employing electronic databases in pharmacies, primary adherence assesses whether the patient received the first prescription whereas secondary adherence is an ongoing process that measures whether the patient received dispensing or refills as prescribed during a defined observation period (3). Medication persistence implies that the patient must have exhibited at least primary adherence, as it cannot be measured unless the patient has received the first dispensing (3). The two most commonly used secondary adherence medication measures are the Medication Possession Ratio (MPR) and the Proportion of Days Covered (PDC) (2). These two measures are closely related as they are both refill record-based adherence measurements.

Many mobile phone apps are available to support people in taking their medications and to therefore improve medication adherence $(4,5)$. However, a recent meta-analysis found that the majority did not have many of the desirable features and were of low quality (4).

It is known that adherence to treatment is low in allergic diseases and asthma $(6,7)$. Mobile technology may help to better understand the adherence and its determinants as well how to improve adherence to treatment (8). MPR and PDC are of interest. They have been applied on mobile technology (9) but cannot be used directly in anonymized app users as there is usually no information on prescription. Thus, the concepts of MPR and PDC should be modified when using data gathered from such apps.

MASK-rhinitis (Mobile Airways Sentinel Network for allergic rhinitis) is a patient-centered ICT (information and communication technologies) system (10). A mobile phone app (the Allergy Diary) central to MASK is available in 22 countries. It has been validated (11) and was found to be an easy and effective method of assessing symptoms of AR and work productivity (11-14). MASK follows the checklist for the evaluation of Good Practices developed by the European Union Joint Action JACHRODIS (Joint Action on Chronic Diseases and Promoting Healthy Ageing across the Life Cycle) (15).

The aim of this study was to assess the adherence to treatment in allergic rhinitis patients using the Allergy Diary App.

This article is protected by copyright. All rights reserved. 


\section{Methods}

\section{Design of the study}

An observational cross-sectional study was carried out on all users who filled in the Allergy Diary from January 1, 2016 to August 1, 2017. Five visual analogue scales (VAS) assessed the daily control of the disease (i.e. global evaluation of allergic symptoms, nose, eyes, asthma and work) (16). Since users are anonymized and cannot be contacted, we could not use an adherence questionnaire such as the Morisky $(17,18)$. The paper was written according to the STROBE checklist.

Inclusion criteria: people who had allergic rhinitis, who used the Allergy Diary, who completed at least 7 days (not necessarily consecutive) of symptom recording (VAS global score), and who continued to use the same AR medication over the study period.

\section{Setting}

Users from 22 countries filled in the Allergy Diary (Table 4). The Allergy Diary is available in 16 languages (translated and back-translated, culturally adapted and legally compliant).

\section{Users}

All consecutive users who registered to the Allergy Diary were included if they had filled in the VAS global measured. The Allergy Diary is filled in independently from the presence/absence of symptoms. There were no exclusion criteria for participation in the Allergy Diary initiative. Basic demographic characteristics (age, sex, country and language) were recorded. The Allergy Diary was used by people who found it on the internet, Apple store, Google Play or in any other way. Some users were patients who were asked by their physicians to use the app. However, due to anonymization of data, specific information could not be gathered as previously described in detail $(12,13)$. The diagnosis of allergic rhinitis is based on the question "I have allergic rhinitis" but all users had rhinitis symptoms (11-14).

\section{Allergy Diary and outcomes}

The Allergy Diary collects information on AR symptoms experienced (nasal and ocular), disease type (intermittent/persistent), how symptoms impact users' lives, and type(s) of AR treatment used. Geolocalized users assess their daily symptom control via the touchscreen functionality on their smart phone: they click on 5 consecutive VAS measures (VAS-global measured, VAS-nasal, VAS-

This article is protected by copyright. All rights reserved. 
ocular, VAS-asthma and VAS-work). Levels range from zero (not at all bothersome) to 100 (very bothersome). Independency of VAS questions was previously assessed using the Bland and Altman regression analysis $(13,19)$. Users input their daily medications using a scroll list which contains all country-specific OTC and prescribed medications available (Figure 1 online). The list has been populated using IMS data.

Some of the VAS data used in this study have been analyzed in other studies with a different aim including work productivity (12) and assessment of treatment or multimorbidity (papers submitted). Moreover, the time frame of the three other studies was different.

\section{Ethics}

The Allergy Diary is CE1 registered. The terms of use have been translated into all languages and customized according to the legislation of each country. This thereby allows the use of the results for research purposes. The data are anonymized - including the geolocalized data - using k-anonymity (20-22). An Independent Review Board approval was not needed for this observational study.

\section{Assessment of adherence}

1- Definitions used: Several adherence calculation methods are based on tablet counts, electronic monitoring by medication containers, patient diaries, and use of adjudicated prescription claims from administrative databases. However, using the Allergy Diary, MPR and PDC with the IPSOR terminology cannot be directly calculated using a classical method (23). They can however be approached. In the present paper, we used:

- Proportion of medication possession ratio (modified MPR): ratio of days that medication was reported to be used on days in a given time interval (see definitions 2 and 3 for further details)

- Proportion of days covered over a time interval (modified PDC): ratio of days that medication was reported to be used on days in the time interval between the first and the last record considered (i.e. the first and the last day in which the VAS about symptoms control is filled in)

2- Number of days with VAS reported: a cut-off of at least 7 records of VAS was set up to ensure an adequate amount of data which assess adherence. Therefore, only users matching this cut-off were enrolled/included in the study.

This article is protected by copyright. All rights reserved. 
3- Predetermined Time interval: The first 14 records were analyzed since the duration of symptoms in AR is usually short (24):

- In users who reported 7 to 14 days of data/symptom recording, we analyzed the total number of days of recording.

- In users who reported over 14 days of data/symptom recording, only the first 14 were analyzed.

- Data in duplicate (reporting, for the same day, 2 assessments) and multiplicate (reporting, for the same day, more than 2 assessments) have occurred ( $<10 \%$ of subjects).

- For 7 records, any duplicate led to the withdrawal of the user.

- For 8 records, 1 duplicate was allowed.

- For 9 records, 2 duplicates were allowed.

- For $\geq 10$ records, 3 duplicates were allowed.

- Thus, all users with less than 7 records were withdrawn.

4- Medication possession ratio (modified MPR): We proposed that:

- The same rhinitis treatment should be used during the time interval. No change in treatment for rhinitis was accepted and change represents an exclusion criteria. However, treatment for asthma was not considered and may vary.

- Based on an accepted adherence level $\geq 70 \%$, the minimum number of days of data recording/collection was determined (Table 1).

- The modified MPR score was calculated as:

$\frac{\text { days of reported treatment }}{\text { time interval (as determined by predetermined time interval) }}$

\section{5- Proportion of days covered over a time interval (modified PDC)}

Both continuous and discontinuous/intermittent reporting was monitored/evaluated. We defined 5 levels of adherence depending on the modified PDC (Table 2)

- The first and last days of data recording were identified and defined the time interval.

- The dates of reporting within the time interval were assessed and counted.

This article is protected by copyright. All rights reserved. 
- For duplicates or multiplicates, the number considered was the exact number $(1,2,3 \ldots)$.

- The modified PDC score was calculated as:

$$
\frac{\text { days of reporting }}{\text { time interval (as determined by first and last day of use) }}
$$

- A number of recorded days greater than the time interval considered indicates that the user is taking more drugs than the initial treatment. We used two levels of PDC $\leq 1.25$ (adherent user to time interval as defined by first and last days of recording and $\leq 1.5$ (adherent or partly-adherent user to time interval as defined by first and last day of recording). Combining PDC $\leq 1.25$ or $\leq 1.5$ with MPR values, 4 groups were defined (Table 3 ).

\section{Biases}

In this study, we did not include the types of treatment used due to the significant variability between treatment recommendations in different countries and no clear pattern of treatment being easily identified from the data collected.

Although MASK can be used to assess medication adherence, there are biases which should be considered: (i) In the literature, there is no clear definition on what is considered "adherent" or "non-adherent", in terms of app usage; (ii) It is not known whether adherence with an app in any way reflects adherence with either medication or control; (iii) Users are anonymized, it is impossible to know how people use apps and the results may not reflect their daily AR management; (iv) It is possible that they take more medications than reported by the App as they may forget to register their daily symptoms.

\section{Sample Size}

In this exploratory study, all registered users who fulfilled the inclusion criteria over the study period were included in order to obtain the best possible estimates for the specified time window.

\section{Statistical analysis}

For normally distributed data, means and SD were used.

This article is protected by copyright. All rights reserved. 


\section{Results}

\section{Characteristics of the user}

A total number of 12,143 users were registered in the Allergy Diary during the observational period. 6,949 users reported at least one VAS data recording. A total of 64,566 VAS recordings were made. Among them, 1,887 users reported $\geq 7$ VAS data (Figure 1). There were $888(47 \%)$ males and 999 (53\%) females. They had a median age of 32 years (25-75 percentiles: $22-44$ years). The repartition of user by country is presented in Table 4.

\section{Overall results}

Overall results are presented in Table 5. Only 136 (11.28\%) users were adherent (MPR $\geq 70 \%$ and PDC < 1.25). In addition, 51 (4.23\%) users were partly adherent (MPR $\geq 70 \%$ and PDC $=1.50$ ), and 176 (14.60\%) were switchers, defined as users who did not use the same medication but for the defined interval (MPR $\geq 70 \%$ and PDC > 1.50). On the other hand, 832 (69.05\%) users were non-adherent to medications (MPR<70\%). Of those, the largest group was non-adherent to medications and the time interval was increased in 442 (36.68\%) users.

For a number of days reported under 15 to 20 , users were vastly non-adherent (MPR<70). On the other hand, above this level, users were more adherent to medications (PDC) than before. It therefore seems that users who reported VAS levels over 15 days are more likely to be adherent. Moreover, the median level of time interval was different between groups, suggesting that discontinuous treatment is associated with poorer medication adherence.

\section{Discussion}

Our study was characterized by information retrieved from patients from 22 countries. To our knowledge, this is the first study to perform an evaluation of medication adherence based on data retrieved from a mobile app using a routine way/real life setting. This study shows the very low adherence to treatment in AR patients in a real-life setting.

This article is protected by copyright. All rights reserved. 


\section{Strengths and limitations}

The strengths and limitations of this study are those of mobile technology, as previously discussed $(12,13,25)$. There are potential measurement biases when using apps since the information collected is usually restricted and less complete than when using more detailed paper or web-based questionnaires. App users may be a selected subset and therefore not fully representative of all AR patients. Higher education or specific age ranges might apply. The study was not meant to be representative of the general population. Precise patient characterization is impossible via an App used in real life, but every observational study using the Allergy Diary gave highly consistent results with a clear clinical perspective (11-14). Users self-reported the diagnosis of rhinitis but this was confirmed by the questionnaire on rhinitis and conjunctivitis symptoms included in the App. Mobile technology is likely to become an important tool to better understand and manage AR and asthma.

Other limitations should also be considered. Among a high number of users, only a relatively low number were constantly filling information on treatment in the app and we only considered users reporting over 6 days. We did not analyse the type of treatment due to its great variability. This will be done when more data become available and using machine learning approaches. Another limitation is that the app is based on the unsupervised input of data. There is, therefore, a bias related to potentially missing data input. Nevertheless, our study took the opportunity of analysing real-world adherence and designing new methodologies for analysing such data.

We did not include a questionnaire on medication adherence since users report their daily medications.

\section{Discussion of results}

Our data show that about $70 \%$ of AR patients filling data over 6 days (27.2\% of the entire database) are non-adherent to medications. Only $11.3 \%$ of AR users filling data over 6 days were fully adherent to medications and time interval (MPR $\geq 70 \%$ and PDC $\leq 1.25$ ).

Few studies reported the prevalence of adherence in AR patients in the real-life context. $35 \%$ of patients were non-adherent for some time during the treatment and $38 \%$ indicated that they discontinued treatment when they felt better $(26,27)$. One study, carried out in the outpatient setting, suggests that a short message service (SMS) helps to improve AR treatment (28).

This article is protected by copyright. All rights reserved. 
Adherence in randomized control trials is high but does not reflect the real-life situation $(29,30)$ and alternative measurement of adherence in a real-life setting is needed. The best studies would be using electronic devices that count and record the drugs taken. However, these devices are expensive and, as such, not a viable solution for large studies in AR patients (31). Considering that we live in an era of "digital revolution" and that a huge percentage of people have a smartphone, mobile applications appeared as a good alternative to improve patient control over their illness. Such $\mathrm{m}$-health technology has enormous potential to be used as a reliable, cost-effective and usable tool, not only for AR, but also for other diseases $(26,32,33)$. Although there are already some mhealth tools for allergic rhinitis, there are few studies evaluating their benefits and impact (26). There is a growing understanding of barriers to adherence and ways to overcome them. The development of mAdherence tools to explore barriers to maintaining engagement is growing and will be important in the development of mHealth interventions.

There is no gold standard for measuring adherence to medication. There are mainly direct and indirect measures. All methods have their limitations, so it is highly recommended to combine more than one (34). In this study, we used a combination of MPR and PDC, the most used measures of secondary adherence. We defined adherence as MPR $\geq 70 \%$ and $P D C \leq 1.25$. Results were grouped by PDC value by using a cut-off value of 1.25 . Therefore, the resulting groups had PDC $\leq 1.25$ and PDC>1.25 respectively. It was possible to verify that, although with some differences, both follow the same trend. Under 15 to 20 days, patients were mostly non-adherent, and there are some theories that can explain this such as that for many patients AR is only intermittent and that the most troublesome symptoms can be managed with a short course of medication. There are several subtypes of allergic rhinitis and, depending on the type and severity of the condition, the treatment may be different. AR can be described as a seasonal condition, therefore some patients may present persistent symptoms while others may present symptoms only when the allergen is present. On the other hand, above 15 days of VAS reported, patients tend to be more adherent, which may also be a result of more severe symptoms, leading to continuous treatment $(27,35)$ or to a better adherence in people reporting longer periods of use. It would be important to also study the attitudinal and behavioural clusters of individuals who continue to monitor and treat their AR above 15 days. Insights from research in asthma suggest that determining attitudinal clusters can provide insights into medication use and taking behaviour (36). All the participants were volunteers and anonymous, making them very remote from direct clinical input. Also, patients had no sense of being watched over (Hawthorn effect) which prevents a biased increase in adherence. In RCTs, adherence is likely to be much higher (37). Further research is needed to understand how patients can be motivated to use and app regularly and the role of the healthcare professional in suggesting that the app is used

This article is protected by copyright. All rights reserved. 
as a means of assisting the patient to better understand their disease, monitor their symptoms and promote adherence.

\section{Conclusion}

This is the first paper to present adherence to AR treatment in a real-world setting from a European population sample. From a methodological point of view, this study highlights the opportunity to measure secondary adherence from an app (modified MPR and modified PDC). From a clinical point of view, this study gives the opportunity to discuss the gap that exists between theory and real word evidence, based on data from real practice, paving the way for a change management in allergic rhinitis. Further information will derive from the ongoing recruitment of Allergy Diary users. AR treatment is based on concepts that do not necessarily apply to real life. All recommendations propose a continuous treatment rather than an on-demand use (38). Our results show that adherence to treatment is low. The relative efficacy of continuous versus on-demand treatment for AR symptoms is still a matter of debate (39). In general, medical use (if achieved), non-anonymised and linked to the patients' electronic health-records, may be higher because of the Hawthorn effect $(40,41)$. However, a requirement to use the app to gain assistance should always be offered without any coercion. In other words, careful patient counselling is required. Moreover, in real life, patients rarely follow treatment indications (guidelines). Finally, the use of such an app in the context of routine clinical care may present the opportunity to describe different Allergic Rhinitis (and NonAllergic Rhinitis) phenotypes, each of which may potentially have its own adherence pattern (to app usage and treatment) and may ultimately help to identify early on which patients might benefit from specialist assessment.

This article is protected by copyright. All rights reserved. 


\section{References}

1. Vrijens B, De Geest S, Hughes DA, Przemyslaw K, Demonceau J, Ruppar T, et al ; ABC Project Team. A new taxonomy for describing and defining adherence to medications. Br J Clin Pharmacol. 2012 May;73(5):691-705.

2. Cramer JA, Roy A, Burrell A, Fairchild CJ, Fuldeore MJ, Ollendorf DA, et al. Medication compliance and persistence: terminology and definitions. Value Health. 2008;11(1):44-7.

3. Raebel MA, Schmittdiel J, Karter AJ, Konieczny JL, Steiner JF. Standardizing terminology and definitions of medication adherence and persistence in research employing electronic databases. Med Care. 2013;51(8 Suppl 3):S11-21.

4. Santo K, Richtering SS, Chalmers J, Thiagalingam A, Chow CK, Redfern J. Mobile Phone Apps to Improve Medication Adherence: A Systematic Stepwise Process to Identify High-Quality Apps. JMIR Mhealth Uhealth. 2016;4(4):e132.

5. Thakkar J, Kurup R, Laba TL, Santo K, Thiagalingam A, Rodgers A, et al. Mobile Telephone Text Messaging for Medication Adherence in Chronic Disease: A Meta-analysis. JAMA Intern Med. 2016;176(3):340-9.

6. Hasford J, Uricher J, Tauscher M, Bramlage P, Virchow JC. Persistence with asthma treatment is low in Germany especially for controller medication - a population based study of 483,051 patients. Allergy. 2010;65(3):347-54.

7. Makhinova T, Barner JC, Richards KM, Rascati KL. Asthma Controller Medication Adherence, Risk of Exacerbation, and Use of Rescue Agents Among Texas Medicaid Patients with Persistent Asthma. J Manag Care Spec Pharm. 2015;21(12):1124-32.

8. Vasbinder EC, Goossens LM, Rutten-van Molken MP, de Winter BC, van Dijk L, Vulto AG, et al. eMonitoring of Asthma Therapy to Improve Compliance in children (e-MATIC): a randomised controlled trial. Eur Respir J. 2016;48(3):758-67.

9. Anglada-Martinez H, Martin-Conde M, Rovira-Illamola M, Sotoca-Momblona JM, Sequeira E, Aragunde V, et al. Feasibility and Preliminary Outcomes of a Web and Smartphone-Based Medication Self-Management Platform for Chronically III Patients. J Med Syst. 2016;40(4):99.

10. Bousquet J, Hellings PW, Agache I, Bedbrook A, Bachert C, Bergmann KC, et al. ARIA 2016: Care pathways implementing emerging technologies for predictive medicine in rhinitis and asthma across the life cycle. Clin Transl Allergy. 2016;6:47.

11. Caimmi D, Baiz N, Tanno LK, Demoly P, Arnavielhe S, Murray R, et al. Validation of the MASKrhinitis visual analogue scale on smartphone screens to assess allergic rhinitis control. Clin Exp Allergy. 2017;47(12):1526-1533.

This article is protected by copyright. All rights reserved. 
12. Bousquet J, Bewick M, Arnavielhe S, Mathieu-Dupas E, Murray R, Bedbrook A, et al. Work productivity in rhinitis using cell phones: The MASK pilot study. Allergy. 2017;72(10):1475-1484.

13. Bousquet J, Caimmi DP, Bedbrook A, Bewick M, Hellings PW, Devillier P, et al. Pilot study of mobile phone technology in allergic rhinitis in European countries: the MASK-rhinitis study. Allergy. 2017;72(6):857-65.

14. Bousquet J, Arnavielhe S, Bedbrook A, Fonseca J, Morais Almeida M, Todo Bom A, et al. The ARIA score of allergic rhinitis using mobile technology correlates with quality-of-life: The MASK study. Allergy. 2018;73(2):505-510..

15. Bousquet J, Onorato GL, Bachert C, Barbolini M, Bedbrook A, Bjermer L, et al. CHRODIS criteria applied to the MASK (MACVIA-ARIA Sentinel NetworK) Good Practice in allergic rhinitis: a SUNFRAIL report. Clin Transl Allergy. 2017;7:37.

16. Klimek L, Bergmann K, Biederman T, Bousquet J, Hellings P, al e. Visual analogue scales (VAS): measuring instruments for the documentation of symptoms and therapy monitoring in allergic rhinitis in everyday health care. Position Paper of the German Society of Allergology. Allergo J Int. 2017;26(1):16-24.

17. Menditto E, Guerriero F, Orlando V, Crola C, Di Somma C, Illario M, et al. Self-Assessment of Adherence to Medication: A Case Study in Campania Region Community-Dwelling Population. J Aging Res. 2015;2015:682503.

18. Morisky DE, Green LW, Levine DM. Concurrent and predictive validity of a self-reported measure of medication adherence. Med Care. 1986;24(1):67-74.

19. Bland JM, Altman DJ. Regression analysis. Lancet. 1986;1(8486):908-9.

20. Aristodimou A, Antoniades A, Pattichis CS. Privacy preserving data publishing of categorical data through k-anonymity and feature selection. Healthc Technol Lett. 2016;3(1):16-21.

21. El Emam K, Dankar FK. Protecting privacy using k-anonymity. J Am Med Inform Assoc. 2008;15(5):627-37.

22. Sweeney L. k-anonymity: a model for protecting privacy. Int J Uncertain Fuz Knowl Syst. 2002;10(5):557-70.

23. Kozma CM, Dickson M, Phillips AL, Meletiche DM. Medication possession ratio: implications of using fixed and variable observation periods in assessing adherence with disease-modifying drugs in patients with multiple sclerosis. Patient Prefer Adherence. 2013;7:509-16.

24. Price D, Scadding G, Ryan D, Bachert C, Canonica GW, Mullol J, et al. The hidden burden of adult allergic rhinitis: UK healthcare resource utilisation survey. Clin Transl Allergy. 2015;5:39.

This article is protected by copyright. All rights reserved. 
25. Bousquet J, Arnavielhe S, Bedbrook A, Alexis-Alexandre G, Eerd Mv, Murray R, et al. Treatment of allergic rhinitis using mobile technology with real world data: The MASK observational pilot study. Allergy. 2018:doi:10.1111/all.13406.

26. Huang X, Matricardi PM. Allergy and Asthma Care in the Mobile Phone Era. Clin Rev Allergy Immunol. 2016. Epub ahead of print.

27. Bender BG. Motivating patient adherence to allergic rhinitis treatments. Curr Allergy Asthma Rep. 2015;15(3):10.

28. Wang $\mathrm{K}$, Wang $\mathrm{C}, \mathrm{Xi} \mathrm{L}$, Zhang $\mathrm{Y}$, Ouyang $\mathrm{Y}$, Lou $\mathrm{H}$, et al. A randomized controlled trial to assess adherence to allergic rhinitis treatment following a daily short message service (SMS) via the mobile phone. Int Arch Allergy Immunol. 2014;163(1):51-8.

29. Belknap R, Holland D, Feng PJ, Millet JP, Caylà JA, Martinson NA, et al ; TB Trials Consortium iAdhere Study Team. Self-administered Versus Directly Observed Once-Weekly Isoniazid and Rifapentine Treatment of Latent Tuberculosis Infection: A Randomized Trial. Ann Intern Med. 2017 Nov 21;167(10):689-697

30. Sulaiman I, Greene G, MacHale E, Seheult J, Mokoka M, D'Arcy S, et al. A randomised clinical trial of feedback on inhaler adherence and technique in patients with severe uncontrolled asthma. Eur Respir J. 2018 Jan 4;51(1).

31. Passalacqua G, Baiardini I, Senna G, Canonica GW. Adherence to pharmacological treatment and specific immunotherapy in allergic rhinitis. Clin Exp Allergy. 2013;43(1):22-8.

32. Joshi S, Dimov V. Use of new technology to improve utilization and adherence to immunotherapy. World Allergy Organ J. 2014;7(1):29.

33. Braido F, Baiardini I, Puggioni F, Garuti S, Pawankar R, Walter Canonica G. Rhinitis: adherence to treatment and new technologies. Curr Opin Allergy Clin Immunol. 2017;17(1):23-7.

34. Lieber S, Helcer J, Shemesh E. Monitoring drug adherence. Transplant Rev (Orlando). 2015;29(2):73-7.

35. Greiwe JC, Bernstein JA. Combination therapy in allergic rhinitis: What works and what does not work. Am J Rhinol Allergy. 2016;30(6):391-6.

36. David-Wang A, Price D, Cho SH, Ho JC, Liam CK, Neira G, Teh PL; REcognise Asthma and LInk to Symptoms and Experience (REALISE) Asia Working Group. Development and Validation of an Attitudinal-Profiling Tool for Patients With Asthma. Allergy Asthma Immunol Res. 2017 Jan;9(1):43-51.

37. Costa DJ, Amouyal M, Lambert P, Ryan D, Schünemann HJ, Daures JP, Bousquet J, Bousquet PJ; Languedoc-Roussillon Teaching General Practitioners Group. How representative are clinical

This article is protected by copyright. All rights reserved. 
study patients with allergic rhinitis in primary care? J Allergy Clin Immunol. 2011 Apr;127(4):920-6.e1.

38. Single maintenance and reliever therapy (SMART) for asthma DTB 2011;49:126-129.

39. Wartna JB, Bohnen AM, Elshout G, Pijnenburg MW, Pols DH, Gerth van Wijk RR, et al. Symptomatic treatment of pollen-related allergic rhinoconjunctivitis in children: randomized controlled trial. Allergy. 2017;72(4):636-44.

40. Malhotra S, Musgrave SD, Pinnock H, Price D, Ryan DP. The challenge of recruiting in primary care for a trial of telemonitoring in asthma: an observational study. Pragmat Obs Res. 2012 Aug 23;3:51-55.

41. McCambridge J, Witton J, Elbourne DR. Systematic review of the Hawthorne effect: new concepts are needed to study research participation effects. J Clin Epidemiol. 2014 Mar;67(3):267-77.

This article is protected by copyright. All rights reserved. 
Table 1: Modified MPR cut-off for the assessment of medication adherence

\begin{tabular}{|ccc|} 
Time interval* $^{*}$ & Data on treatment* & $\begin{array}{c}\text { Medication adherence** } \\
\text { (Modified MPR) }\end{array}$ \\
\hline $\mathbf{7}$ & 5 & $71.4 \%$ \\
\hline $\mathbf{8}$ & 6 & $75.0 \%$ \\
\hline $\mathbf{9}$ & 7 & $77.8 \%$ \\
\hline $\mathbf{1 0}$ & 7 & $70.0 \%$ \\
\hline $\mathbf{1 1}$ & 8 & $72.7 \%$ \\
\hline $\mathbf{1 2}$ & 9 & $75.0 \%$ \\
\hline 13 & 10 & $76.9 \%$ \\
\hline 14 & 10 & $71.4 \%$ \\
\hline
\end{tabular}

*: Results expressed in days. **accepted cut-off for adherence is Modified MPR $>70 \%$

This article is protected by copyright. All rights reserved. 
Table 2: Number of days assessed to calculate the modified PDC

\begin{tabular}{|cccccc|}
$\begin{array}{c}\text { Time } \\
\text { interval* }\end{array}$ & $\mathbf{1}$ & $\mathbf{1 . 2 5}$ & $\mathbf{1 . 5}$ & $\mathbf{2}$ & $\geq 2$ \\
\hline $\mathbf{7}$ & $\mathbf{7}$ & 9 & 10 & 14 & $\geq 15$ \\
\hline $\mathbf{8}$ & 8 & 10 & 12 & 16 & $\geq 17$ \\
\hline $\mathbf{9}$ & 9 & 11 & 13 & 18 & $\geq 19$ \\
\hline $\mathbf{1 0}$ & 10 & 12 & 15 & 20 & $\geq 21$ \\
\hline $\mathbf{1 1}$ & 11 & 14 & 16 & 22 & $\geq 23$ \\
\hline $\mathbf{1 2}$ & 12 & 15 & 18 & 24 & $\geq 25$ \\
\hline $\mathbf{1 3}$ & 13 & 16 & 19 & 26 & $\geq 27$ \\
\hline $\mathbf{1 4}$ & 14 & 17 & 21 & 28 & $\geq 29$ \\
\hline
\end{tabular}

*Results expressed in days

Table 3: Definition of groups for adherence

\begin{tabular}{|c|c|c|c|}
\hline PDC Criteria & MPR Criteria & Descriptor & \\
\hline$\leq 1.25$ or 1.5 & $\geq 70 \%$ & $\begin{array}{l}\text { Users who always used the same } \\
\text { medication for the defined time interval }\end{array}$ & Adherent user \\
\hline$\leq 1.25$ or 1.5 & $<70 \%$ & $\begin{array}{l}\text { Users who always used the same } \\
\text { medication but at a time greater than the } \\
\text { defined time interval }\end{array}$ & Partly adherent user \\
\hline$>1.25$ or 1.5 & $\geq 70 \%$ & $\begin{array}{l}\text { Users who did not use the same } \\
\text { medication for the defined interval }\end{array}$ & Non-adherent user \\
\hline$>1.25$ or 1.5 & $<70 \%$ & $\begin{array}{l}\text { Users who did not use the same } \\
\text { medication and at a time greater than } \\
\text { the defined time interval }\end{array}$ & Non-adherent user \\
\hline
\end{tabular}

This article is protected by copyright. All rights reserved. 
Table 4: Repartition of users per country

\begin{tabular}{|lr|}
\hline Country & Users \\
\hline Australia & 11 \\
Austria & 51 \\
Belgium & 15 \\
Brazil & 98 \\
Canada & 3 \\
Czech Republic & 3 \\
Denmark & 19 \\
Finland & 50 \\
France & 53 \\
Germany & 172 \\
Great Britain & 97 \\
Greece & 78 \\
Italy & 228 \\
Lithuania & 149 \\
Mexico & 344 \\
Netherlands & 46 \\
Poland & 75 \\
Portugal & 183 \\
Spain & 157 \\
Sweden & 32 \\
Switzerland & 87 \\
Turkey & \\
\hline Total & 57 \\
\hline
\end{tabular}

This article is protected by copyright. All rights reserved. 
Table 5: Overall results: number of users depending on MPR, PDC and duration of reporting

\begin{tabular}{|c|c|c|c|c|c|c|c|c|c|c|c|}
\hline Modified MPR & & $\geq 70 \%$ & & & & & $0 \%$ & & & & Total users \\
\hline Modified PDC & 1 & 1.25 & 1.5 & 2 & $>2$ & 1 & 1.25 & 1.5 & 2 & $>2$ & \\
\hline 7 days & 4 & 5 & 5 & 5 & 11 & 6 & 5 & 5 & 10 & 41 & 97 \\
\hline 8 days & 3 & 3 & 6 & 5 & 11 & 2 & 14 & 8 & 4 & 41 & 97 \\
\hline 9 days & 0 & 1 & 2 & 1 & 25 & 1 & 2 & 6 & 4 & 35 & 77 \\
\hline 10 days & 5 & 2 & 0 & 2 & 8 & 2 & 4 & 6 & 10 & 32 & 71 \\
\hline 11 days & 2 & 2 & 0 & 2 & 10 & 2 & 2 & 1 & 7 & 19 & 47 \\
\hline 12 days & 0 & 2 & 0 & 2 & 5 & 0 & 2 & 18 & 3 & 12 & 44 \\
\hline 13 days & 0 & 0 & 1 & 3 & 11 & 1 & 5 & 2 & 10 & 16 & 49 \\
\hline 14 days & 0 & 3 & 1 & 7 & 8 & 2 & 3 & 7 & 6 & 17 & 54 \\
\hline 15 days & 0 & 2 & 2 & 0 & 3 & 2 & 5 & 1 & 5 & 13 & 33 \\
\hline 16 days & 0 & 1 & 2 & 1 & 6 & 4 & 3 & 6 & 3 & 9 & 35 \\
\hline 17 days & 0 & 1 & 4 & 3 & 3 & 2 & 3 & 6 & 4 & 7 & 33 \\
\hline 18 days & 2 & 2 & 1 & 0 & 3 & 4 & 1 & 1 & 2 & 7 & 23 \\
\hline 19 days & 0 & 3 & 3 & 2 & 2 & 1 & 3 & 2 & 1 & 3 & 20 \\
\hline 20-22 days & 5 & 6 & 2 & 4 & 3 & 7 & 10 & 12 & 4 & 14 & 67 \\
\hline 23-24 days & 7 & 1 & 5 & 0 & 4 & 7 & 2 & 4 & 6 & 7 & 43 \\
\hline $25-29$ days & 2 & 5 & 3 & 1 & 4 & 10 & 15 & 16 & 3 & 8 & 67 \\
\hline 30-34 days & 5 & 9 & 4 & 4 & 4 & 9 & 10 & 11 & 9 & 12 & 77 \\
\hline 35-39 days & 3 & 3 & 1 & 1 & 0 & 12 & 8 & 7 & 5 & 8 & 48 \\
\hline $40-49$ days & 5 & 7 & 2 & 3 & 3 & 12 & 7 & 8 & 11 & 10 & 68 \\
\hline 50-59 days & 3 & 5 & 0 & 2 & 1 & 7 & 13 & 4 & 5 & 3 & 43 \\
\hline $60-74$ days & 5 & 9 & 3 & 2 & 0 & 4 & 13 & 1 & 4 & 3 & 44 \\
\hline 75-99 days & 4 & 6 & 4 & 1 & 0 & 6 & 10 & 5 & 4 & 4 & 44 \\
\hline$>100$ days & 1 & 2 & 0 & 0 & 0 & 3 & 7 & 0 & 0 & 1 & 14 \\
\hline Total users & 56 (4.68\%) & 80 (6.69\%) & $51(4.26 \%)$ & $51(4.26 \%)$ & $125(10.46 \%)$ & $106(8.87 \%)$ & $147(12.30 \%)$ & 137 (11.46\%) & $120(10.04 \%)$ & $322(26.94 \%)$ & $1195(100 \%)$ \\
\hline
\end{tabular}

This article is protected by copyright. All rights reserved. 


\section{Figure 1: Flow chart of users}

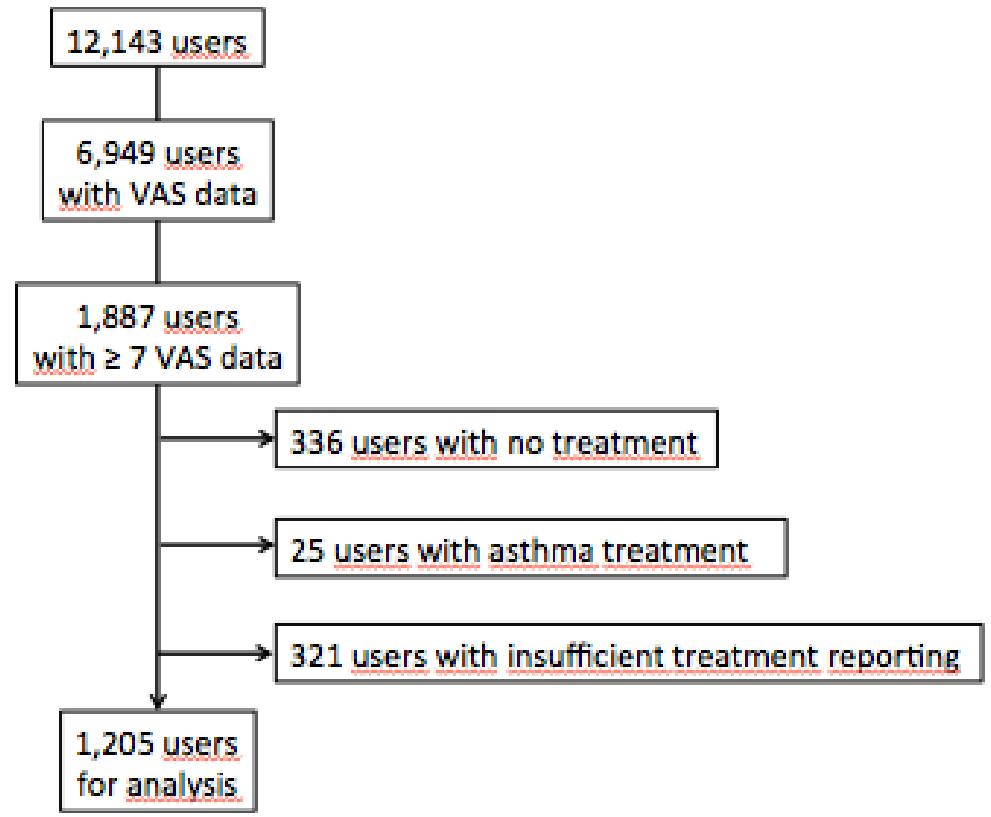

MASK Study group

J Bousquet ${ }^{1-3}$, PW Hellings ${ }^{4}$, W Aberer ${ }^{5}$, I Agache ${ }^{6}$, CA Akdis ${ }^{7}$, M Akdis ${ }^{7}$, MR Aliberti $^{8}$, R Almeida ${ }^{9}$, F Amat ${ }^{10}$, R Angles ${ }^{11}$, I Annesi-Maesano ${ }^{12}$, IJ Ansotegui ${ }^{13}$, JM Anto ${ }^{14-17}$, S Arnavielle ${ }^{18}$, E Asayag ${ }^{19}$, A Asarnoj ${ }^{20}, \mathrm{H}$ Arshad $^{21}$, F Avolio ${ }^{22}$, E Bacci ${ }^{23}, \mathrm{C}$ Bachert ${ }^{24}$, I Baiardini ${ }^{25}, \mathrm{C}$ Barbara ${ }^{26}$, M Barbagallo ${ }^{27}$, I Baroni ${ }^{28}$, BA Barreto ${ }^{29}$, X Basagana ${ }^{14}$, ED Bateman ${ }^{30}, \mathrm{M}$ Bedolla-Barajas $^{31}$, A Bedbrook $^{2}$, M Bewick ${ }^{32}$, B Beghé $^{33}$, EH Bel ${ }^{34}, \mathrm{KC}$ Bergmann ${ }^{35}, \mathrm{KS}$ Bennoor $^{36}, \mathrm{M}$ Benson $^{37}$, L Bertorello ${ }^{23}$, AZ Białoszewski ${ }^{38}$, T Bieber $^{39}$, S Bialek ${ }^{40}, \mathrm{C}$ BindslevJensen ${ }^{41}$, L Bjermer ${ }^{42}, \mathrm{H}$ Blain ${ }^{43,44}, \mathrm{~F}$ Blasi ${ }^{45}$, A Blua ${ }^{46}, \mathrm{M}$ Bochenska Marciniak ${ }^{47}$, I Bogus-Buczynska ${ }^{47}, \mathrm{AL}$ Boner ${ }^{48}, \mathrm{M}$ Bonini ${ }^{49}$, S Bonini ${ }^{50}$, CS Bosnic-Anticevich ${ }^{51}$, I Bosse ${ }^{52}$, J Bouchard ${ }^{53}$, LP Boulet ${ }^{54}$, R Bourret ${ }^{55}$, PJ Bousquet ${ }^{12}$, F Braido ${ }^{25}$, V Briedis ${ }^{56}$, CE Brightling ${ }^{57}$, J Brozek ${ }^{58}$, C Bucca ${ }^{59}$, R Buhl ${ }^{60}$, R Buonaiuto ${ }^{61}, \mathrm{C}$ Panaitescu ${ }^{62}$, MT Burguete Cabañas ${ }^{63}$, E Burte ${ }^{3}$, A Bush ${ }^{64}$, $\mathrm{F}$ Caballero-Fonseca $^{65}$, D Caillaud ${ }^{67}$, D Caimmi ${ }^{68}$, MA Calderon ${ }^{69}$, PAM Camargos ${ }^{70}$, T Camuzat $^{71}$, G Canfora $^{72}$, GW Canonica ${ }^{25}$, V Cardona ${ }^{73}, \mathrm{KH} \mathrm{Carlsen}^{74}, \mathrm{P}$

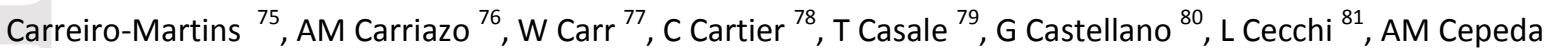
${ }^{82}$, NH Chavannes ${ }^{83}$, Y Chen ${ }^{84}$, R Chiron ${ }^{68}$, $\mathrm{T}$ Chivato ${ }^{85}$, E Chkhartishvili ${ }^{86}$, AG Chuchalin ${ }^{87}$, KF Chung ${ }^{88}$, MM Ciaravolo ${ }^{89}$, A Ciceran ${ }^{90}, \mathrm{C}$ Cingi ${ }^{91}, \mathrm{G}$ Ciprandi ${ }^{92}$, AC Carvalho Coehlo ${ }^{93}$, L Colas ${ }^{94}$, E Colgan ${ }^{95}$, J Coll ${ }^{96}, \mathrm{D}$ Conforti ${ }^{97}$, J Correia de Sousa ${ }^{98}$, RM Cortés-Grimaldo ${ }^{99}$, F Corti ${ }^{100}$, E Costa ${ }^{101}$, MC Costa-Dominguez ${ }^{102}$, AL Courbis ${ }^{103}$, L Cox ${ }^{104}$, M Crescenzo ${ }^{105}$, AA Cruz ${ }^{106}$, A Custovic ${ }^{107}$, W Czarlewski ${ }^{108}$, SE Dahlen ${ }^{109}$, G D'Amato ${ }^{381}$, C Dario ${ }^{110}$, J da Silva ${ }^{111}$, Y Dauvilliers ${ }^{112}$, U Darsow ${ }^{113}$, F De Blay ${ }^{114}$, G De Carlo ${ }^{115}$, T Dedeu ${ }^{116}$, M de Fátima Emerson ${ }^{117}$, G De Feo ${ }^{118}$, G De Vries ${ }^{119}$, B De Martino, ${ }^{120}$ NP Motta Rubina ${ }^{121}$, D Deleanu ${ }^{122}$, P Demoly ${ }^{12,68}$, JA Denburg ${ }^{123}$, P Devillier ${ }^{124}$, S Di Capua Ercolano ${ }^{125}$, N Di Carluccio ${ }^{66}$, A Didier ${ }^{126}$, D Dokic ${ }^{127}$, MG Dominguez-Silva ${ }^{128}$, H Douagui ${ }^{129}$, G Dray ${ }^{103}$, R Dubakiene ${ }^{130}$, SR Durham ${ }^{131}$, G Du Toit ${ }^{132}$, MS Dykewicz ${ }^{133}, \mathrm{Y}$ El-Gamal ${ }^{134}$, P Eklund ${ }^{135}$, E Eller ${ }^{41}$, R Emuzyte ${ }^{136}$, J Farrell ${ }^{95}$, A Farsi ${ }^{81}$, J Ferreira de Mello Jr ${ }^{137}$, J Ferrero ${ }^{138}$, A Fink-Wagner ${ }^{139}$, A Fiocchi ${ }^{140}$, WJ Fokkens ${ }^{141}$, JA Fonseca ${ }^{142}$, JF Fontaine ${ }^{143}$, S Forti ${ }^{97}$, JM Fuentes-Perez ${ }^{144}$, JL Gálvez-Romero ${ }^{145}$, A Gamkrelidze ${ }^{146}$, J Garcia-Aymerich ${ }^{14}$, CY García-Cobas ${ }^{147}$, MH Garcia-Cruz ${ }^{148}$, B Gemicioğlu ${ }^{149}$, S Genova ${ }^{150}$, G Christoff ${ }^{151}$, JE Gereda ${ }^{152}$, R Gerth van Wijk ${ }^{153}$, RM Gomez ${ }^{154}$, J Gómez-Vera 155, S González Diaz ${ }^{156}$, M Gotua ${ }^{157}$, I Grisle ${ }^{158}$, M Guidacci ${ }^{159}$, NA Guldemond ${ }^{160}$, Z Gutter ${ }^{161}$, MA Guzmán ${ }^{162}$ , T Haahtela ${ }^{163}$, J Hajjam ${ }^{164}$, L Hernández ${ }^{165}$, JO'B Hourihane ${ }^{166}$, YR Huerta-Villalobos ${ }^{167}$, M Humbert ${ }^{168}$, G

This article is protected by copyright. All rights reserved. 
laccarino ${ }^{169}$, M Illario ${ }^{170}$, Z Ispayeva ${ }^{380}$, JC Ivancevich ${ }^{171}$, EJ Jares ${ }^{172}$, E Jassem ${ }^{173}$, SL Johnston ${ }^{174}$, G Joos ${ }^{175}$, KS Jung ${ }^{176}$, J Just ${ }^{10}$, M Jutel ${ }^{177}$, I Kaidashev ${ }^{178}$, O Kalayci ${ }^{179}$, AF Kalyoncu ${ }^{180}$, J Karjalainen ${ }^{181}$, P Kardas ${ }^{182}$, T Keil ${ }^{183}$, PK Keith ${ }^{184}$, M Khaitov ${ }^{185}$, N Khaltaev ${ }^{186}$, J Kleine-Tebbe ${ }^{187}$, L Klimek ${ }^{188}$, ML Kowalski ${ }^{189}$, M Kuitunen ${ }^{190}$, I Kull ${ }^{191}$, P Kuna ${ }^{47}$, M Kupczyk ${ }^{47}$, V Kvedariene ${ }^{192}$, E Krzych-Fałta ${ }^{193}$, P Lacwik ${ }^{47}$, D Larenas-Linnemann ${ }^{194}$, D Laune ${ }^{18}$, D Lauri ${ }^{195}$, J Lavrut ${ }^{196}$, LTT Le ${ }^{197}$, M Lessa ${ }^{198}$, G Levato ${ }^{199}$, J Li ${ }^{200}$, P Lieberman ${ }^{201}$, A Lipiec ${ }^{193}$, B Lipworth ${ }^{202}$, KC Lodrup Carlsen ${ }^{203}$, R Louis ${ }^{204}$, O Lourenço ${ }^{205}$, JA Luna-Pech ${ }^{206}$, A Magnan ${ }^{94}$, B Mahboub ${ }^{207}$, D Maier ${ }^{208}$, A Mair ${ }^{209}$, I Majer ${ }^{210}$, J Malva ${ }^{211}$, E Mandajieva ${ }^{212}$, P Manning ${ }^{213}$, E De Manuel Keenoy ${ }^{214}$, GD Marshall ${ }^{215}$, MR Masjedi ${ }^{216}$, JF Maspero ${ }^{217}$, E Mathieu-Dupas ${ }^{18}$, JJ Matta Campos ${ }^{218}$, AL Matos ${ }^{219}$, M Maurer ${ }^{220}$, S Mavale-Manuel ${ }^{221}$, O Mayora ${ }^{97}$, MA Medina-Avalos ${ }^{222}$, E Melén ${ }^{223}$, E Melo-Gomes ${ }^{26}$, EO Meltzer ${ }^{224}$, E Menditto ${ }^{225}$, J Mercier ${ }^{226}$, N Miculinic ${ }^{227}$, F Mihaltan ${ }^{228}$, B Milenkovic ${ }^{229}$, G Moda ${ }^{230}$, MD Mogica-Martinez ${ }^{231}$, Y Mohammad ${ }^{232}$, I Momas 233,234 , S Montefort ${ }^{235}$, R Monti ${ }^{236}$, D Mora Bogado ${ }^{237}$, M Morais-Almeida ${ }^{238}$, FF Morato-Castro ${ }^{239}$, R Mösges ${ }^{240}$, A Mota-Pinto ${ }^{241}$, P Moura Santo ${ }^{242}$, J Mullol ${ }^{243}$, L Münter ${ }^{244}$, A Muraro ${ }^{245}, \mathrm{R}$ Murray ${ }^{246}$, R Naclerio ${ }^{247}$, $\mathrm{R} \mathrm{Nadif}^{3}$, M Nalin ${ }^{28}$, L Napoli ${ }^{248}$, L Namazova-Baranova ${ }^{249}, \mathrm{H}$ Neffen ${ }^{250}$, V Niedeberger ${ }^{251}$, K Nekam ${ }^{252}$, A Neou ${ }^{253}$, A Nieto ${ }^{254}$, L Nogueira-Silva ${ }^{255}$, M Nogues ${ }^{2,256}$, E Novellino ${ }^{257}$, TD Nyembue ${ }^{258}$, RE O'Hehir ${ }^{259}$, C Odzhakova ${ }^{260}$, K Ohta ${ }^{261}$, Y Okamoto ${ }^{262}$, K Okubo ${ }^{263}$, GL Onorato ${ }^{2}$, M Ortega Cisneros ${ }^{264}$, S Ouedraogo ${ }^{265}$, I Pali-Schöll ${ }^{266}$, S Palkonen ${ }^{115}$, P Panzner ${ }^{267}$, NG Papadopoulos ${ }^{268}$, HS Park ${ }^{269}$, A Papi ${ }^{270}$, G Passalacqua ${ }^{271}$, E Paulino ${ }^{272}$, R Pawankar ${ }^{273}$, S Pedersen ${ }^{274}$, JL Pépin ${ }^{275}$, AM Pereira ${ }^{276}$, M Persico 277, O Pfaar ${ }^{278,279}$, J Phillips ${ }^{280}$, R Picard ${ }^{281}$, B Pigearias ${ }^{282}$, I Pin ${ }^{283}$, C Pitsios ${ }^{284}$, D Plavec ${ }^{285}$, W Pohl ${ }^{286}$, TA Popov ${ }^{287}$, F Portejoie ${ }^{2}$, P Potter ${ }^{288}$, AC Pozzi ${ }^{289}$, D Price ${ }^{290}$, EP Prokopakis ${ }^{291}$, R Puy ${ }^{259}$, B Pugin ${ }^{292}$, RE Pulido Ross ${ }^{293}$, M Przemecka ${ }^{47}$, KF Rabe ${ }^{294}$, F Raciborski ${ }^{193}$, R Rajabian-Soderlund ${ }^{295}$, S Reitsma ${ }^{141}$, I Ribeirinho ${ }^{296}$, J Rimmer ${ }^{297}$, D Rivero-Yeverino ${ }^{298}$, JA Rizzo ${ }^{299}$, MC Rizzo ${ }^{300}$, C Robalo-Cordeiro ${ }^{301}$, F Rodenas ${ }^{302}$, X Rodo ${ }^{14}$, M Rodriguez Gonzalez, ${ }^{303}$, L Rodriguez-Mañas ${ }^{304}$, C Rolland ${ }^{305}$, S Rodrigues Valle ${ }^{306}$, M Roman Rodriguez ${ }^{307}$, A Romano ${ }^{308}$, E Rodriguez-Zagal ${ }^{309}$, G Rolla ${ }^{310}$, RE Roller-Wirnsberger ${ }^{311}$, M Romano ${ }^{28}$, J Rosado-Pinto ${ }^{312}$, N. Rosario ${ }^{313}$, M Rottem ${ }^{314}$, D Ryan ${ }^{315}$, H Sagara ${ }^{316}$, J Salimäki ${ }^{317}$, B Samolinski ${ }^{193}$, M Sanchez-Borges ${ }^{318}$, J Sastre-Dominguez ${ }^{319}$, GK Scadding ${ }^{320}$, HJ Schunemann ${ }^{58}$, N Scichilone ${ }^{321}$, P Schmid-Grendelmeier ${ }^{322}$, FS Serpa ${ }^{323}$, S Shamai ${ }^{240}$, A Sheikh ${ }^{324}$, M Sierra ${ }^{96}$, FER Simons ${ }^{325}$, V Siroux ${ }^{326}$, JC Sisul ${ }^{327}$, I Skrindo ${ }^{378}$, D Solé ${ }^{328}$, D Somekh ${ }^{329}$, M Sondermann ${ }^{330}$, T Sooronbaev ${ }^{331}$, M Sova ${ }^{332}$, M Sorensen, ${ }^{333}$ M Sorlini ${ }^{334}$, O Spranger ${ }^{139}, \mathrm{C}$ Stellato ${ }^{118}$, R Stelmach ${ }^{335}$, R Stukas ${ }^{336}$, J Sunyer ${ }^{14-17}$, J Strozek ${ }^{193}$, A Szylling ${ }^{193}$, JN Tebyriçá ${ }^{337}$, M Thibaudon ${ }^{338}$, T To $^{339}$, A Todo-Bom ${ }^{340}$, PV Tomazic ${ }^{341}$, S Toppila-Salmi ${ }^{163}$, U Trama ${ }^{342}$, M Triggiani ${ }^{118}$, C Suppli Ulrik ${ }^{343}$, M Urrutia-Pereira ${ }^{344}$, R Valenta ${ }^{345}$, A Valero ${ }^{346}$, A Valiulis ${ }^{347}$, E Valovirta ${ }^{348}$, M van Eerd ${ }^{119}$, E van Ganse ${ }^{349}$, M van Hague ${ }^{350}$, O Vandenplas ${ }^{351}$, MT Ventura ${ }^{352}$, G Vezzani ${ }^{353}$, T Vasankari ${ }^{354}$, A Vatrella ${ }^{118}$, MT Verissimo ${ }^{211}$, F Viart ${ }^{78}$, G Viegi ${ }^{355}$, D Vicheva ${ }^{356}$, T Vontetsianos ${ }^{357}$, M Wagenmann ${ }^{358}$, S Walker ${ }^{359}$, D Wallace ${ }^{360}$, DY Wang ${ }^{361}$, S Waserman ${ }^{362}$, T Werfel ${ }^{363}$, M Westman ${ }^{364}$, M Wickman ${ }^{191}$, DM Williams ${ }^{365}$, S Williams ${ }^{366}$, N Wilson ${ }^{379}$, J Wright ${ }^{367}$, P Wroczynski ${ }^{40}$, P Yakovliev ${ }^{368}$, BP Yawn ${ }^{369}$, PK Yiallouros ${ }^{370}$, A Yorgancioglu ${ }^{371}$, OM Yusuf ${ }^{372}, \mathrm{HJ}$ Zar $^{373}$, L Z Zhang ${ }^{374}$, N Zhong ${ }^{200}$, ME Zernotti ${ }^{375}$, I Zhanat, ${ }^{380}$, M Zidarn ${ }^{376}$, T Zuberbier ${ }^{35}$, C Zubrinich ${ }^{259}$, A Zurkuhlen ${ }^{377}$

This article is protected by copyright. All rights reserved. 


\section{MASK Study group}

University Hospital, Montpellier, France.

2. MACVIA-France, Fondation partenariale FMC VIA-LR, Montpellier, France.

VIMA. INSERM U 1168, VIMA : Ageing and chronic diseases Epidemiological and public health approaches, Villejuif, Université Versailles St-Quentin-en-Yvelines, UMR-S 1168, Montigny le Bretonneux, France and Euforea, Brussels, Belgium. Laboratory of Clinical Immunology, Department of Microbiology and Immunology, KU Leuven, Leuven, Belgium. Department of Dermatology, Medical University of Graz, Graz, Austria.

Transylvania University Brasov, Brasov, Romania.

Swiss Institute of Allergy and Asthma Research (SIAF), University of Zurich, Davos, Switzerland.

Project Manager, Chairman of the Council of Municipality of Salerno, Italy.

Center for Health Technology and Services Research- CINTESIS, Faculdade de Medicina, Universidade do Porto; and Medida, Lda Porto, Portugal.

10.

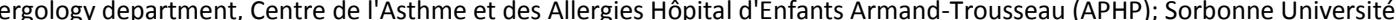
UPMC Univ Paris 06, UMR_S 1136, Institut Pierre Louis d'Epidémiologie et de Santé Publique, Equipe EPAR, Paris, France. Innovación y nuevas tecnologías, Salud Sector sanitario de Barbastro, Barbastro, Spain. Epidemiology of Allergic and Respiratory Diseases, Department Institute Pierre Louis of Epidemiology and Public Health, INSERM and Sorbonne Université, Medical School Saint Antoine, Paris, France Department of Allergy and Immunology, Hospital Quirón Bizkaia, Erandio, Spain. ICREA and Climate and Health (CLIMA) Program, ISGlobal, Barcelona, Spain. IMIM (Hospital del Mar Research Institute), Barcelona, Spain.

CIBER Epidemiología y Salud Pública (CIBERESP), Barcelona, Spain.

Universitat Pompeu Fabra (UPF), Barcelona, Spain.

KYomed INNOV, Montpellier, France.

Argentine Society of Allergy and Immunopathology, Buenos Aires, Argentina.

Clinical Immunology and Allergy Unit, Department of Medicine Solna, Karolinska Institutet, Stockholm, and Astrid Lindgren Children's Hospital, Department of Pediatric Pulmonology and Allergy, Karolinska University Hospital, Stockholm, Sweden. David Hide Asthma and Allergy Research Centre, Isle of Wight, United Kingdom.

Regionie Puglia, Bari, Italy.

Regione Liguria, Genoa, Italy.

Upper Airways Research Laboratory, ENT Dept, Ghent University Hospital, Ghent, Belgium.

Allergy and Respiratory Diseases, Ospedale Policlinico San Martino, University of Genoa, Italy.

PNDR, Portuguese National Programme for Respiratory Diseases, Faculdade de Medicina de Lisboa, Lisbon, Portugal.

Director of the Geriatric Unit, Department of Internal Medicine (DIBIMIS), University of Palermo, Italy.

Telbios SRL, Milan, Italy.

Universidade do Estado do Pará, Belem, Brazil.

Department of Medicine, University of Cape Town, Cape Town, South Africa.

Hospital Civil de Guadalajara Dr Juan I Menchaca, Guadalarara, Mexico.

iQ4U Consultants Ltd, London, UK.

Section of Respiratory Disease, Department of Oncology, Haematology and Respiratory Diseases, University of Modena and Reggio Emilia, Modena, Italy.

34.

Department of Respiratory Medicine, Academic Medical Center (AMC), University of Amsterdam, The Netherlands.

35.

( Universitätsmedizin Berlin, corporate member of Freie Universität Berlin, Humboldt-Universität zu Berlin, and Berlin Institute of Health, Comprehensive Allergy Center, Department of Dermatology and Allergy, Global Allergy and Asthma European Network (GA ${ }^{2}$ LEN), Berlin, Germany.

36. Dept of Respiratory Medicine, National Institute of Diseases of the Chest and Hospital, Dhaka, Bangladesh.

37. Centre for Individualized Medicine, Department of Pediatrics, Faculty of Medicine, Linköping, Sweden.

Department of Prevention of Environmental Hazards and Allergology, Medical University of Warsaw, Poland. BIEBER. Department of Dermatology and Allergy, Rheinische Friedrich-Wilhelms-University Bonn, Bonn, Germany Dept of Biochemistry and Clinical Chemistry, University of Pharmacy with the Division of Laboratory Medicine, Warsaw Medical University, Warsaw, Poland. Department of Dermatology and Allergy Centre, Odense University Hospital, Odense Research Center for Anaphylaxis (ORCA), Odense, Denmark.

42.

43.

44.

45.

Department of Respiratory Medicine and Allergology, University Hospital, Lund, Sweden.

Department of Geriatrics, Montpellier University Hospital, Montpellier, France.

EA 2991, Euromov, University Montpellier, France.

Policlinico, Milan, Italy.

46. Argentine Association of Respiratory Medicine, Buenos Aires, Argentina.

47. Division of Internal Medicine, Asthma and Allergy, Barlicki University Hospital, Medical University of Lodz, Poland.

48. Pediatric Department, University of Verona Hospital, Verona, Italy.

49. UOC Pneumologia, Istituto di Medicina Interna, F. Policlinico Gemelli IRCCS, Università Cattolica del Sacro Cuore, Rome, Italy, and National Heart and Lung Institute, Royal Brompton Hospital \& Imperial College London, UK.

50. Second University of Naples and Institute of Translational Medicine, Italian National Research Council.

51. Woolcock Institute of Medical Research, University of Sydney and Woolcock Emphysema Centre and Local Health District, Glebe, NSW, Australia.

Allergist, La Rochelle, France.

52. 
56.

57.

58.

59.

60.

61.

62.

63.

64.

65.

66.

67.

68.

69.

70.

71.

72.

73.

74.

75.

76.

77.

78.

79.

80.

81.

82.

83.

84.

85.

86.

87.

88.

89.

90.

91.

92.

93.

94.

95.

96.

97.

98.

99.

100

101.

102.

103.

104.

105.

106.

107.

108.

109.

110.

111.

112.

113

114.

Head of Department of Clinical Pharmacy of Lithuanian University of Health Sciences, Kaunas, Lithuania.

Institute of Lung Health, Respiratory Biomedical Unit, University Hospitals of Leicester NHS Trust, Leicestershire, UK;

Department of Infection, Immunity and Inflammation, University of Leicester, Leicester, UK.

Department of Health Research Methods, Evidence and Impact, Division of Immunology and Allergy, Department of Medicine,

McMaster University, Hamilton, ON, Canada.

Chief of the University Pneumology Unit- AOU Molinette, Hospital City of Health and Science of Torino, Italy.

Universitätsmedizin der Johannes Gutenberg-Universität Mainz, Mainz, Germany.

Pharmacist, Municipality Pharmacy, Sarno, Italy.

University of Medicine and Pharmacy Victor Babes, Timisoara, Romania.

Instituto de Pediatria, Hospital Zambrano Hellion Tec de Monterrey, Monterrey, Mexico.

Imperial College and Royal Brompton Hospital, London, UK.

Centro Medico Docente La Trinidad, CaRacas, Venezuela.

Regional Director Assofarm Campania and Vice President of the Board of Directors of Cofaser, Salerno, Italy

Service de pneumologie, CHU et université d'Auvergne, Clermont-Ferrand, France.

Department of Respiratory Diseases, Montpellier University Hospital, France.

Imperial College London - National Heart and Lung Institute, Royal Brompton Hospital NHS, London, UK.

Federal University of Minas Gerais, Medical School, Department of Pediatrics, Belo Horizonte, Brazil

Assitant Director General, Montpellier, Région Occitanie, France.

Mayor of Sarno and President of Salerno Province, Director, Anesthesiology Service, Sarno "Martiri del Villa Malta" Hospital, Italy.

Allergy Section, Department of Internal Medicine, Hospital Vall d'Hebron \& ARADyAL Spanish Research Network, Barcelona, Spain.

Department of Paediatrics, Oslo University Hospital and University of Oslo, Oslo, Norway.

CEDOC, Integrated Pathophysiological Mechanisms Research Group, Nova Medical School, Campo dos Martires da Patria,

Lisbon, and Serviço de Imunoalergologia, Centro Hospitalar de Lisboa Central, EPE, Lisbon, Portugal.

Regional Ministry of Health of Andalusia, Seville, Spain.

Allergy and Asthma Associates of Southern California, Mission Viejo, CA, USA.

ASA - Advanced Solutions Accelerator, Clapiers, France.

Division of Allergy/Immunology, University of South Florida, Tampa, Fla, USA

Celentano pharmacy, Massa Lubrense, Italy.

SOS Allergology and Clinical Immunology, USL Toscana Centro, Prato, Italy.

Allergy and Immunology Laboratory, Metropolitan University Hospital, Branquilla, Columbia.

Department of Public Health and Primary Care, Leiden University Medical Center, Leiden, The Netherlands

Capital Institute of Pediatrics, Chaoyang district, Beijing, China.

School of Medicine, University CEU San Pablo, Madrid, Spain.

David Tvildiani Medical University - AIETI Highest Medical School, David Tatishvili Medical Center Tbilisi, Georgia.

Pulmonolory Research Institute FMBA, Moscow, Russia and GARD Executive Committee, Moscow, Russia.

National Heart \& Lung Institute, Imperial College, London, UK.

Specialist social worker, Sorrento, Italy.

Argentine Federation of Otorhinolaryngology Societies, Buenos Aires, Argentina.

Eskisehir Osmangazi University, Medical Faculty, ENT Department, Eskisehir,Turkey.

Medicine Department, IRCCS-Azienda Ospedaliera Universitaria San Martino, Genoa, Italy.

Universidade Federal da Bahia, Escola de Enfermagem, Brazil.

Plateforme Transversale d'Allergologie, Institut du Thorax, CHU de Nantes, Nantes, France.

LANUA International Healthcare Consultancy, Northern Ireland, UK.

Innovación y nuevas tecnologías, Salud Sector sanitario de Barbastro, Barbastro, Spain

Innovation and Research Office, Department of Health and Social Solidarity, Autonomous Province of Trento, Italy.

Life and Health Sciences Research Institute (ICVS), School of Medicine, University of Minho, Braga, Portugal; ICVS/3B's, PT

Government Associate Laboratory, Braga/Guimarães, Portugal.

Servicio de Allergologia, Hospital Angeles del Carmen, Guadalajara, Mexico.

FIMMG (Federazione Italiana Medici di Medicina Generale), Milan, Italy.

UCIBIO, REQUINTE, Faculty of Pharmacy and Competence Center on Active and Healthy Ageing of University of Porto

(Porto4Ageing), Porto, Portugal.

Allergologo, Mexico City, Mexico.

IMT Mines Alès, Unversité Montpellier, Alès, France.

Department of Medicine, Nova Southeastern University, Davie, University of Miami Dept of Medicine, Miami, Florida, USA.

Regional Director Assofarm Campania and Vice President of the Board of Directors of Cofaser, Salerno, Italy.

ProAR - Nucleo de Excelencia em Asma, Federal University of Bahia, Brasil and WHO GARD Planning Group, Brazil.

Centre for Respiratory Medicine and Allergy, Institute of Inflammation and Repair, University of Manchester and University Hospital of South Manchester, Manchester, UK.

Medical Consulting Czarlewski, Levallois, France.

The Centre for Allergy Research, The Institute of Environmental Medicine, Karolinska Institutet, Stockholm, Sweden.

Azienda Provinciale per i Servizi Sanitari di Trento (APSS-Trento), Italy.

Department of Internal Medicine and Allergy Clinic of Professor Polydoro Ernani de São Thiago University Hospital, Federal

University of Santa Catarina (UFSC), Florianópolis, Santa Catarina, Brazil.

Sleep Unit, Department of Neurology, Hôpital Gui-de-Chauliac Montpellier, Inserm U1061, France.

Department of Dermatology and Allergy, Technische Universität München, Munich, Germany; ZAUM-Center for Allergy and

Environment, Helmholtz Center Munich, Technische Universität München, Munich, Germany.

Allergy Division, Chest Disease Department, University Hospital of Strasbourg, Strasbourg, France.

This article is protected by copyright. All rights reserved. 
EFA European Federation of Allergy and Airways Diseases Patients' Associations, Brussels, Belgium AQuAS, Barcelna, Spain \& EUREGHA, European Regional and Local Health Association, Brussels, Belgium Policlínica Geral do Rio de Janeiro, Rio de Janeiro - Brasil Department of Medicine, Surgery and Dentistry "Scuola Medica Salernitana", University of Salerno, Salerno, Italy Peercode BV, Geldermalsen, The Netherlands.

Social workers oordinator, Sorrento, Italy.

Federal University of the State of Rio de Janeiro, School of Medicine and Surgery, Rio de Janeiro, Brazil Allergology and Immunology Discipline, "Iuliu Hatieganu" University of Medicine and Pharmacy, Cluj-Napoca, Romania. Department of Medicine, Division of Clinical Immunology and Allergy, McMaster University, Hamilton, Ontario, Canada. Laboratoire de Pharmacologie Respiratoire UPRES EA220, Hôpital Foch, Suresnes, Université Versailles Saint-Quentin, Université Paris Saclay, France.

Farmacie Dei Golfi Group, Massa Lubrense, Italy.

Rangueil-Larrey Hospital, Respiratory Diseases Department, Toulouse, France.

University Clinic of Pulmology and Allergy, Medical Faculty Skopje, Republic of Macedonia.

Allergologo, Mexico City, Mexico.

Service de Pneumo-Allergologie, Centre Hospitalo-Universitaire de Béni-Messous, Algiers, Algeria.

Clinic of infectious, chest diseases, dermatology and allergology, Vilnius University, Vilnius, Lithuania.

Allergy and Clinical Immunology National Heart and Lung Institute, Imperial College London, UK.

Guy's and st Thomas' NHS Trust, Kings College London, UK.

Section of Allergy and Immunology, Saint Louis University School of Medicine, Saint Louis, Missouri, USA.

Pediatric Allergy and Immunology Unit, Children's Hospital, Ain Shams University, Cairo, Egypt.

Department of Computing Science, Umeå University, Sweden and Four Computing Oy, Finland.

Clinic of Children's Diseases, Faculty of Medicine, Vilnius University, Vilnius, Lithuania.

University of São Paulo Medical School, Sao Paulo, Brazil

Andalusian Agency for Healthcare Quality, Seville, Spain

Global Allergy and Asthma Platform GAAPP, Vienna, Austria.

Division of Allergy, Department of Pediatric Medicine - The Bambino Gesù Children's Research Hospital Holy see, Rome, Italy. Department of Otorhinolaryngology, Academic Medical Centers, Amsterdam, the Netherlands.

CINTESIS, Center for Research in Health Technologies and Information Systems, Faculdade de Medicina da Universidade do Porto, Porto, Portugal and MEDIDA, Lda, Porto, Portugal

Allergist, Reims, France.

Hospital General Regional 1 "Dr Carlos Mc Gregor Sanchez Navarro" IMSS, Mexico City, Mexico.

Regional hospital of ISSSTE, Puebla, Mexico.

National Center for Disease Control and Public Health of Georgia, Tbilisi, Georgia.

Allergologo, Guadalajara, Mexico.

Allergy Clinic, National Institute of Respiratory Diseases, Mexico City, Mexico.

Department of Pulmonary Diseases, Istanbul University-Cerrahpasa, Cerrahpasa Faculty of Medicine, Istambul,Turkey.

Allergology unit, UHATEM "NIPirogov", Sofia, Bulgaria.

Medical University, Faculty of Public Health, Sofia, Bulgaria.

Allergy and Immunology Division, Clinica Ricardo Palma, Lima, Peru.

Department of Internal Medicine, section of Allergology, Erasmus MC, Rotterdam, The Netherlands.

Allergy \& Asthma Unit, Hospital San Bernardo Salta, Argentina.

Allergy Clinic, Hospital Regional del ISSSTE 'Lic. López Mateos', Mexico City, Mexico.

Head and Professor, Centro Regional de Excelencia CONACYT y WAO en Alergia, Asma e Inmunologia, Hospital Universitario,

Universidad Autónoma de Nuevo León, Monterrey NL, Mexico.

Center of Allergy and Immunology, Georgian Association of Allergology and Clinical Immunology, Tbilisi, Georgia.

Latvian Association of Allergists, Center of Tuberculosis and Lung Diseases, Riga, Latvia.

Federal District Base Hospital Institute, Brasília, Brazil.

Institute of Health Policy and Management iBMG, Erasmus University, Rotterdam, The Netherlands.

University Hospital Olomouc - National eHealth Centre, Czech Republic.

Immunology and Allergy Division, Clinical Hospital, University of Chile, Santiago, Chile.

Skin and Allergy Hospital, Helsinki University Hospital, University of Helsinki, Helsinki, Finland.

Centich : centre d'expertise national des technologies de l'information et de la

communication pour l'autonomie, Gérontopôle autonomie longévité des Pays de la Loire, Conseil régional des Pays de la Loire, Centre d'expertise Partenariat Européen d'Innovation pour un vieillissement actif et en bonne santé, Nantes, France.

Autonomous University of Baja California, Ensenada, Baja California, Mexico.

Department of Paediatrics and Child Health, University College Cork, Cork, Ireland.

Hospital General Regional 1 “Dr. Carlos MacGregor Sánchez Navarro” IMSS, Mexico City, Mexico.

Université Paris-Sud; Service de Pneumologie, Hôpital Bicêtre; Inserm UMR_S999, Le Kremlin Bicêtre, France.

Dipartimento di medicina, chirurgia e odontoiatria, università di Salerno, Italy.

Division for Health Innovation, Campania Region and Federico II University Hospital Naples (R\&D and DISMET) Naples, Italy. Servicio de Alergia e Immunologia, Clinica Santa Isabel, Buenos Aires, Argentina.

President, Libra Foundation, Buenos Aires, Argentina.

Medical University of Gdańsk, Department of Allergology, Gdansk, Poland.

Airway Disease Infection Section, National Heart and Lung Institute, Imperial College; MRC \& Asthma UK Centre in Allergic

Mechanisms of Asthma, London, UK.

Dept of Respiratory Medicine, Ghent University Hospital, Ghent, Belgium.

Hallym University College of Medicine, Hallym University Sacred Heart Hospital, Gyeonggi-do, South Korea.

Department of Clinical Immunology, Wrocław Medical University, Poland.

Ukrainina Medical Stomatological Academy, Poltava, Ukraine. 
Pediatric Allergy and Asthma Unit, Hacettepe University School of Medicine, Ankara, Turkey. Hacettepe University, School of Medicine, Department of Chest Diseases, Immunology and Allergy Division, Ankara, Turkey Allergy Centre, Tampere University Hospital, Tampere, Finland.

First Department of Family Medicine, Medical University of Lodz, Poland.

Institute of Social Medicine, Epidemiology and Health Economics, Charité - Universitätsmedizin Berlin, Berlin, and Institute for Clinical Epidemiology and Biometry, University of Wuerzburg, Germany.

Department of Medicine, McMaster University, Health Sciences Centre 3V47, West, Hamilton, Ontario, Canada.

National Research Center, Institute of Immunology, Federal Medicobiological Agency, Laboratory of Molecular immunology,

Moscow, Russian Federation.

GARD Chairman, Geneva, Switzerland.

Allergy \& Asthma Center Westend, Berlin, Germany.

Center for Rhinology and Allergology, Wiesbaden, Germany.

Department of Immunology and Allergy, Healthy Ageing Research Center, Medical University of Lodz, Lodz, Poland.

Children's Hospital and University of Helsinki, Finland.

Department of Clinical Science and Education, Södersjukhuset, Karolinska Institutet, Stockholm and Sach's Children and Youth Hospital, Södersjukhuset, Stockholm, Sweden.

Faculty of Medicine, Vilnius University, Vilnius, Lithuania.

Department of Prevention of Envinronmental Hazards and Allergology, Medical University of Warsaw, Poland.

Center of Excellence in Asthma and Allergy, Médica Sur Clinical Foundation and Hospital, México City, Mexico.

Presidente CMMC, Milano, Italy.

Head of the Allergy Department of Pedro de Elizalde Children's Hospital, Buenos Aires, Argentina.

University of Medicine and Pharmacy, Hochiminh City, Vietnam.

Federal University of Bahia, Brazil.

Sifmed, Milano, Italy.

State Key Laboratory of Respiratory Diseases, Guangzhou Institute of Respiratory Disease, the First Affiliated Hospital of Guangzhou Medical University, Guangzhou, China.

Departments of Internal Medicine and Pediatrics (Divisions of Allergy and Immunology), University of Tennessee College of Medicine, Germantown, TN, USA.

Scottish Centre for Respiratory Research, Cardiovascular \& Diabetes Medicine, Medical Research Institute, Ninewells Hospital, University of Dundee, UK. Medicine, Oslo, Norway.

Department of Pulmonary Medicine, CHU Sart-Tilman, and GIGA I3 research group, Liege, Belgium.

Faculty of Health Sciences and CICS - UBI, Health Sciences Research Centre, University of Beira Interior, Covilhã, Portugal. Department of Philosophical, Methodological and Instrumental Disciplines, CUCS, University of Guadalajara, Guadalajara, Mexico.

Department of Pulmonary Medicine, Rashid Hospital, Dubai, UAE.

Biomax Informatics AG, Munich, Germany.

Director General for Health and Social Care, Scottish Government, Edinburgh, UK.

Department of Respiratory Medicine, University of Bratislava, Bratislava, Slovakia.

Coimbra Institute for Clinical and Biomedical Research (iCBR), Faculty of Medicine, University of Coimbra, Portugal;

Ageing@Coimbra EIP-AHA Reference Site, Coimbra, Portugal.

Medical center Iskar Ltd Sofia, Bulgaria.

Department of Medicine (RCSI), Bon Secours Hospital, Glasnevin, Dublin, Ireland.

Kronikgune, International Centre of Excellence in Chronicity Research Barakaldo, Bizkaia, Spain

Division of Clinical Immunology and Allergy, Laboratory of Behavioral Immunology Research, The University of Mississippi

Medical Center, Jackson, Mississippi, USA.

Tobacco Control Research Centre;Iranian Anti Tobacco Association, Tehran, Iran.

Argentine Association of Allergy and Clinical Immunology, Buenos Aires, Argentina

Hospital de Especialidades, Centro Medico Nacional Siglo XXI, Mexico City, Mexico

University of Southeast Bahia, Brazil.

Allergie-Centrum-Charité at the Department of Dermatology and Allergy, Charité - Universitätsmedizin Berlin, Germany

Maputo Central Hospital, Department of Paediatrics, Maputo, Mozambique.

Allergologo, Veracruz, Mexico

Sachs' Children and Youth Hospital, Södersjukhuset, Stockholm and Institute of Environmental Medicine, Karolinska Institutet, Stockholm, Sweden.

Allergy and Asthma Medical Group and Research Center, San Diego, California, USA.

CIRFF, Federico II University, Naples, Italy.

Department of Physiology, CHRU, University Montpellier, Vice President for Research, PhyMedExp, INSERM U1046, CNRS UMR 9214, France.

Croatian Pulmonary Society.

National Institute of Pneumology M Nasta, Bucharest, Romania.

Clinic for Pulmonary Diseases, Clinical Center of Serbia, Faculty of Medicine, University of Belgrade, Serbian Association for Asthma and COPD, Belgrade, Serbia.

Regione Piemonte, Torino, Italy.

Col Jardines de Sta Monica, Tlalnepantla, Mexico.

National Center for Research in Chronic Respiratory Diseases, Tishreen University School of Medicine, Latakia, Syria. Department of Public health and health products, Paris Descartes University-Sorbonne Paris Cité, EA 4064 and Paris Municipal Department of social action, childhood, and health, Paris, France .

Paris municipal Department of social action, childhood, and health, Paris, France. 
Lead Respiratory Physician Mater Dei Hospital Malta, Academic Head of Dept and Professor of Medicine University of Malta, Deputy Dean Faculty of Medicine and Surgery University of Medicine, La Valette, Malta. Department of Medical Sciences, Allergy and Clinical Immunology Unit, University of Torino \& Mauriziano Hospital, Torino, Italy. Instituto de Prevision Social IPS HC, Socia de la SPAAI, Tesorera de la SLAAI, Asuncion, Paraguay.

Allergy Center, CUF Descobertas Hospital, Lisbon, Portugal.

Universidade de São Paulo, São Paulo, Brazil.

Institute of Medical Statistics, and Computational Biology, Medical Faculty, University of Cologne, Germany and CRI-Clinical Research International-Ltd, Hamburg, Germany.

241. General Pathology Institute, Faculty of Medicine, University of Coimbra, Portugal; Ageing@Coimbra EIP-AHA Reference Site, Coimbra, Portugal.

242. Federal University of Bahia, Brazil.

243. Rhinology Unit \& Smell Clinic, ENT Department, Hospital Clínic; Clinical \& Experimental Respiratory Immunoallergy, IDIBAPS, CIBERES, University of Barcelona, Spain.

244. Danish Commitee for Health Education, Copenhagen East, Denmark.

245. Food Allergy Referral Centre Veneto Region, Department of Women and Child Health, Padua General University Hospital, Padua, Italy.

246. Director, Medical Communications Consultant, MedScript Ltd, Dundalk, Co Louth, Ireland and New Zealand, and Honorary Research Fellow, OPC, Cambridge, UK.

247. Johns Hopkins School of Medicine, Baltimore, Maryland, USA.

248. General Manager of COFASER - Pharmacy Services Consortium, Salerno, Italy.

249. Scientific Centre of Children's Health under the MoH, Moscow, Russian National Research Medical University named Pirogov, Moscow, Russia.

250. Director of Center of Allergy, Immunology and Respiratory Diseases, Santa Fe, Argentina Center for Allergy and Immunology, Santa Fe, Argentina.

Dept of Otorhinolaryngology, Medical University of Vienna, AKH, Vienna, Austria.

Hospital of the Hospitaller Brothers in Buda, Budapest, Hungary.

Die Hautambulanz and Rothhaar study center, Berlin, Germany.

Neumología y Alergología Infantil, Hospital La Fe, Valencia, Spain.

Center for Health Technology and Services Research - CINTESIS and Department of Internal Medicine, Centro Hospitalar Sao Joao, Porto, Portugal.

(CA santé au travail du Languedoc-Roussillon (CARST-LR), Montpellier, France.

Director of Department of Pharmacy of University of Naples Federico II, Naples, Italy.

ENT Department, University Hospital of Kinshasa, Kinshasa, Congo.

Department of Allergy, Immunology and Respiratory Medicine, Alfred Hospital and Central Clinical School, Monash University, Melbourne, Victoria, Australia; Department of Immunology, Monash University, Melbourne, Victoria, Australia.

Medical center "Research expert", Varna, Bulgaria.

National Hospital Organization, Tokyo National Hospital, Tokyo, Japan.

Dept of Otorhinolaryngology, Chiba University Hospital, Chiba, Japan.

Dept of Otolaryngology, Nippon Medical School, Tokyo, Japan.

Allergologo, Jalisco, Guadalajara, Mexico.

Centre Hospitalier Universitaire Pédiatrique Charles de Gaulle, Ouagadougou, Burkina Faso.

Dept of Comparative Medicine; Messerli Research Institute of the University of Veterinary Medicine and Medical University, Vienna, Austria.

267. Department of Immunology and Allergology, Faculty of Medicine and Faculty Hospital in Pilsen, Charles University in Prague, Pilsen, Czech Republic.

268. Division of Infection, Immunity \& Respiratory Medicine, Royal Manchester Children's Hospital, University of Manchester, Manchester, UK, and Allergy Department, 2nd Pediatric Clinic, Athens General Children's Hospital "P\&A Kyriakou," University of Athens, Athens, Greece.

Farmacias Holon, Lisbon, Portugal.

Department of Pediatrics, Nippon Medical School, Tokyo, Japan.

University of Southern Denmark, Kolding, Denmark.

Université Grenoble Alpes, Laboratoire HP2, Grenoble, INSERM, U1042 and CHU de Grenoble, France.

Allergy Unit, CUF-Porto Hospital and Institute; Center for Research in Health Technologies and information systems CINTESIS, Universidade do Porto, Portugal.

277. Sociologist, municipality area $\mathrm{n} 33$, Sorrento, Italy.

278. Center for Rhinology and Allergology, Wiesbaden, Germany.

279. Department of Otorhinolaryngology, Head and Neck Surgery, Universitätsmedizin Mannheim, Medical Faculty Mannheim, Heidelberg University, Mannheim, Germany.

280. Centre for empowering people and communites, Dublin, UK.

281. Conseil Général de l'Economie Ministère de l'Economie, de l'Industrie et du Numérique, Paris, France.

282. Société de Pneumologie de Langue Française, Espace francophone de Pneumologie, Paris, France.

283. Département de pédiatrie, CHU de Grenoble, Grenoble France.

284. Medical School, University of Cyprus, Nicosia, Cyprus.

285. Children's Hospital Srebrnjak, Zagreb, School of Medicine, University J.J. Strossmayer, Osijek, Croatia.

286. Karl Landsteiner Institute for Clinical and Experimental Pneumology, Hietzing Hospital, Vienna, Austria.

287. University Hospital 'Sv. Ivan Rilski'", Sofia, Bulgaria.

288. Allergy Diagnostic and Clinical Research Unit, University of Cape Town Lung Institute, Cape Town, South Africa.

289. Vice-Presidente of IML, Milano, Italy. 
Centre of Academic Primary Care, Division of Applied Health Sciences, University of Aberdeen, Aberdeen, United Kingdom ; Observational and Pragmatic Research Institute, Singapore, Singapore.

291. Department of Otorhinolaryngology University of Crete School of Medicine, Heraklion, Greece.

292. European Forum for Research and Education in Allergy and Airway Diseases (EUFOREA), Brussels, Belgium.

293. Allergologo, cancun quintana roo, Mexico.

294. LungenClinic Grosshansdorf, Airway Research Center North, Member of the German Center for Lung Research (DZL), Grosshansdorf, Germany Department of Medicine, Christian Albrechts University, Airway Research Center North, Member of the German Center for Lung Research (DZL), Kiel, Germany. Department of Nephrology and Endocrinology, Karolinska University Hospital, Stockholm, Sweden.

296. Farmácia São Paio, Vila Nova de Gaia, Porto, Portugal.

297. St Vincent's Hospital and University of Sydney, Sydney, New South Wales, Australia.

298. Allergologo, Mexico City, Mexico

299. Serviço de Pneumologia-Hosp das Clinicas UFPE-EBSERH, Recife, Brazil.

300. Universidade Federal de São Paulo, São Paulo, Brazil.

301. Centre of Pneumology, Coimbra University Hospital, Portugal.

302. Polibienestar Research Institute, University of Valencia, Valencia, Spain.

303. Pediatric Allergy and Clinical Immunology, Hospital Angeles Pedregal, Mexico City, Mexico.

304. Getafe University Hospital Department of Geriatrics, Madrid, Spain.

305. Association Asthme et Allergie, Paris, France.

306. Universidade Federal do Rio de Janeiro, Rio de Janeiro, Brazil.

307. Primary Care Respiratory Research Unit Institutode Investigación Sanitaria de Palma IdisPa, Palma de Mallorca, Spain.

308. Allergy Unit, Presidio Columbus, Rome, Catholic University of Sacred Heart, Rome and IRCCS Oasi Maria SS, Troina, Italy.

309. Hospital General, Mexico City, Mexico.

310. Regione Piemonte, Torino, Italy. and Immunology, Medical University of Vienna, Vienna, Austria.

346. Pneumology and Allergy Department CIBERES and Clinical \& Experimental Respiratory Immunoallergy, IDIBAPS, University of Barcelona, Spain.

347. Vilnius University Institute of Clinical Medicine, Clinic of Children's Diseases, and Institute of Health Sciences, Department of Public Health, Vilnius, Lithuania; European Academy of Paediatrics (EAP/UEMS-SP), Brussels, Belgium.

348. Department of Lung Diseases and Clinical Immunology Allergology, University of Turku and Terveystalo allergy clinic, Turku, Finland. 
349. PELyon; HESPER 7425, Health Services and Performance Resarch - Université Claude Bernard Lyon, France.

350. Immunology and Allergy Unit, Department of Medicine Solna, Karolinska Institutet and University Hospital, Stockholm.

351. Department of Chest Medicine, Centre Hospitalier Universitaire UCL Namur, Université Catholique de Louvain, Yvoir, Belgium.

352. University of Bari Medical School, Unit of Geriatric Immunoallergology, Bari, Italy.

353. Pulmonary Unit, Department of Medical Specialties, Arcispedale SMaria Nuova/IRCCS, AUSL di Reggio Emilia, Italy.

354. FILHA, Finnish Lung Association, Helsinki, Finland.

355. Pulmonary Environmental Epidemiology Unit, CNR Institute of Clinical Physiology, Pisa, Italy ; and CNR Institute of Biomedicine and Molecular Immunology "A Monroy", Palermo, Italy.

356. Medical University, Plovdiv, Bulgaria, Department of Otorhinolaryngology, Plovdiv, Bulgaria.

357. Sotiria Hospital, Athens, Greece.

358. Dept of Otorhinolaryngology, Universitätsklinikum Düsseldorf, Germany.

359. Asthma UK, Mansell street, London, UK.

360. Nova Southeastern University, Fort Lauderdale, Florida, USA.

361. Department of Otolaryngology, Yong Loo Lin School of Medicine, National University of Singapore, Singapore, Singapore.

362. Department of Medicine, Clinical Immunology and Allergy, McMaster University, Hamilton, Ontario, Canada.

363. Division of Immunodermatology and Allergy Research, Department of Dermatology and Allergy, Hannover Medical School, Hannover, Germany.

364. Department of Medicine Solna, Immunology and Allergy Unit, Karolinska Institutet and Department of ENT diseases, Karolinska University Hospital, Stockholm, Sweden.

365. Eshelman School of Pharmacy, University of North Carolina, Chapel Hill, NC, USA.

366. International Primary Care Respiratory Group IPCRG, Aberdeen, Scotland.

367. Bradford Institute for Health Research, Bradford Royal Infirmary, Bradford, UK.

368. Allergologyst - Medical College of Medical Faculty, Thracian University, Stara Zagora, Bulgaria.

369. Department of Research, Olmsted Medical Center, Rochester, Minnesota, USA.

370. Cyprus International Institute for Environmental \& Public Health in Association with Harvard School of Public Health, Cyprus University of Technology, Limassol, Cyprus; Department of Pediatrics, Hospital "Archbishop Makarios III", Nicosia, Cyprus.

371. Celal Bayar University Department of Pulmonology, Manisa, Turkey.
372. The Allergy and Asthma Institute, Islamabad, Pakistan.

373. Department of Paediatrics and Child Health, Red Cross Children's

Hospital, and MRC Unit on Child \& Adolescent Health, University of Cape Town, Cape Town, South Africa.

374. Department of Otolaryngology Head and Neck Surgery, Beijing TongRen Hospital and Beijing Institute of Otolaryngology, Beijing, China.

375. Universidad Católica de Córdoba, Córdoba, Argentina.

376. University Clinic of Respiratory and Allergic Diseases, Golnik, Slovenia.

377. Gesundheitsregion KölnBonn - HRCB Projekt GmbH, Kohln, Germany.

378. Akershus University Hospital, Department of Otorhinolaryngology, Akershus, Norway.

379. Chief of Staff, the Northern Health Science Alliance (NHSA) and Director and Founder of Northern Health Matters Ltd, Manchester, UK.

380. President of Kazakhstan Association of Allergology and Clinical Immunology, Department of Allergology and Clinical Immunology of the Kazakh National Medical University, Kazakhstan.

381. Division of Respiratory and Allergic Diseases, Hospital 'A Cardarelli', University of Naples Federico II, Naples, Italy.

\section{CONFLICT OF INTEREST :}

S. Bosnic-Anticevich reports grants from Teva, Boehringer Ingelheim, Sanofi, GSK, AstraZeneca, outside the submitted work.

J. Bousquet reports personal fees and other from Chiesi, Cipla, Hikma, Menarini, Mundipharma, Mylan, Novartis, Sanofi-Aventis, Takeda, Teva, Uriach, other from Kyomed, outside the submitted work.

L. Cecchi reports grants from Menarini, grants from Malesci, outside the submitted work; .

T. Haahtela reports personal fees from Mundipharma, Novartis, OrionPharma, outside the submitted work.

P. Kuna reports personal fees from Adamed, Boehringer Ingelheim, AstraZeneca, Chiesi, FAES, Berlin Chemie, Novartis, Polpharma, Allergopharma, outside the submitted work.

V.Kvedariene has received payment for consultancy from GSK and for lectures from Stallergens Greer, BerlincHemie outsaide the submitted work.

R. Mösges reports personal fees from ALK, allergopharma, Allergy Therapeutics, Friulchem, Hexal, Servier, Klosterfrau, Bayer, FAES, GSK, MSD, Johnson\&Johnson, MEDA, Stada, UCB, Nuvo, Menarini, grants from ASIT biotech, Leti, Optima, BitopAG, Hulka, Ursapharm, grants and personal fees from Bencard, Stallergenes, grants, personal fees and non-financial support from Lofarma, non-financial support from Roxall, Atmos, Bionorica, 
personal fees and non-financial support from Novartis, non-financial support from Otonomy, Ferrero, outside the submitted work.

N. Papadopoulos reports personal fees from Novartis, Faes Farma, BIOMAY, HAL, Nutricia Research, Menarini, Novartis, MEDA, Abbvie, Novartis, MEDA, MSD, MEDA, Omega Pharma, Danone, grants from Menarini outside the submitted work.

O. Pfaar reports grants and personal fees from ALK-Abelló, Allergopharma, Stallergenes Greer, HAL Allergy Holding B.V./HAL Allergie GmbH Bencard Allergie GmbH/Allergy Therapeutics, Lofarma, Biotech Tools S.A., Laboratorios LETI/LETI Pharma, Anergis S.A., personal fees from Novartis Pharma, MEDA Pharma, Mobile Chamber Experts (a GA²LEN Partner), Pohl-Boskamp, Indoor Biotechnologies, grants from Biomay, Nuvo, Circassia personal fees from, Glaxo Smith Kline, outside the submitted work.

T. Zuberbier reports and Organizational affiliations: Commitee member: WHO-Initiative "Allergic Rhinitis and Its Impact on Asthma" (ARIA) Member of the Board: German Society for Allergy and Clinical Immunology (DGAKI) Head: European Centre for Allergy Research Foundation (ECARF) Secretary General: Global Allergy and Asthma European Network (GA ${ }^{2}$ LEN) Member: Committee on Allergy Diagnosis and Molecular Allergology, World Allergy Organization (WAO).

This article is protected by copyright. All rights reserved. 